\title{
Impact of fluidized granular flows into water: Implications for tsunamis generated by pyroclastic flows
}

\author{
A. Bougouin, R. Paris, and O. Roche \\ Université Clermont Auvergne, CNRS, IRD, OPGC, Laboratoire Magmas et Volcans, F-63000 \\ Clermont-Ferrand, France
}

\section{Key Points:}

- Novel laboratory experiments of fluidized granular flows entering water are performed to study tsunamis generated by pyroclastic flows.

- In the near-field region, the wave features are mostly controlled by the mass flux and the volume of the granular material, unlike the water depth.

- Beyond flow conditions, the grain size may affect the wave amplitude as it controls the ability of water to penetrate the granular material.

Corresponding author: A. Bougouin, alexis.bougouin@uca.fr 


\begin{abstract}
Novel laboratory experiments of fluidized granular flows entering water are reported, for the purpose of investigating tsunamis generated by pyroclastic flows. Qualitatively, the impact of a fluidized granular flow into water leads to (i) an initial vertical granular jet over water, (ii) a leading and largest wave, and (iii) a turbulent mixing zone forming a turbidity current. The present study focuses on the leading wave features in the nearfield region, as a function of the mass flux per width $q_{m}$ and the volume per width $v$ of the flow, the maximum water depth $H_{o}$, and the slope angle $\theta$ of the inclined plane. The obtained waves are of Stokes and cnoidal types, for which the generation is mostly controlled by $q_{m}$ and $v$. By contrast, $H_{o}$ plays no role on the wave generation that occurs in the shallowest region. Moreover, a comparison between fluidized granular, dry (nonfluidized) granular, and water flows entering water is addressed under similar flow conditions. The dimensionless amplitude scales as $A / H_{o}=f(\zeta)$, where $\zeta=F r S M \sin \theta$ is a dimensionless parameter depending on the Froude number $F r$, the relative slide thickness $S$, the relative mass $M$, and the slope angle $\theta$. Data of fine fluidized granular, fine dry granular, and water flows collapse on a master curve, which implies that the nature of the flowing material is of lesser importance in the current setup. By contrast, coarse granular flows generate lower amplitude waves, which is attributed to the penetration of water into the porous granular medium.
\end{abstract}

Keywords: Tsunami, pyroclastic density current, fluidized granular flow.

\title{
1 Introduction
}

Tsunamis are long-period waves generated by a sudden displacement of the water surface, which can cause severe human and material damages near coastlines. A historical example is the earthquake-tsunami of December 2004 in Southeast Asia, killing more than 283, 000 people on the coasts of the Indian Ocean (e.g., Lay et al., 2005). Although many tsunamis are triggered by submarine earthquakes, other mechanisms can also trigger these waves such as meteorite impacts (e.g., Wünnemann \& Weiss, 2015), iceberg calvings (e.g., Heller et al., 2019), subaerial and submarine landslides (e.g., Harbitz et al., 2006; Løvholt et al., 2015), or volcanic eruptions (e.g., Paris, 2015). Despite this, tsunami risk assessments and warning systems are mainly structured to deal with earthquaketsunamis, which make populations particularly vulnerable to other source mechanisms (Grezio et al., 2017). In particular, coastal communities living close to active volcanoes are commonly unprepared for tsunamis generated by underwater explosions, slope instabilities (submarine and subaerial landslides, flank collapses), caldera collapses, pyroclastic flows, or shock waves due to large explosions (Paris, 2015). However, volcanic tsunamis are not anecdotal phenomena as they cause about $20 \%$ of fatalities attributable to volcanic activities (Latter, 1981; Tanguy et al., 1998), even without taking into account the recent landslide-tsunami of December 2018 caused by the Anak Krakatau eruption (Indonesia) with a death toll of approximatively 400 people (Grilli et al., 2019; Gouhier \& Paris, 2019).

The entrance of pyroclastic flows into the sea has been reported as one of the major processes for the generation of volcanic tsunamis, that is, representing about $20 \%$ of recorded events (Paris, Switzer, et al., 2014). During the major Krakatau eruption of 1883 , which killed more than 36,000 people on costal areas around the Sunda Strait, a dozen tsunamis were observed (Verbeek, 1886). Four different scenarios have been suggested to explain these waves, namely, large flank collapses, submarine phreatomagmatic explosions, pyroclastic flows, or lateral blasts (Nomanbhoy \& Satake, 1995; De Lange et al., 2001). Numerical models were compared to field data of the Tandjong Priok tide gauge at Batavia-Jakarta (Maeno \& Imanura, 2011). The scenario of pyroclastic flows entering water led to better agreement than for the others, which is concordant with geological data (Carey et al., 2001; Paris, Wassmer, et al., 2014). It is now commonly accepted 
that the impact of pyroclastic flows into the sea was the most likely source mechanism. In contrast, the waves recorded worldwide on maregrams were probably different from those observed in the Sunda Strait. A mechanism of long-period sea waves produced by phase coupling with atmospheric compressional gravity or shock waves has been proposed (Yokoyama, 1987). The tsunamis of the caldera-forming eruption of Santorini in the Late Bronze Age are also interpreted as a combination of pyroclastic flows reaching water and of slumping of submarine pyroclastic materials (Nomikou et al., 2016). Recently, several observations of tsunamis following the entrance of pyroclastic flows into the sea have been reported during the Rabaul 1994 eruption (Nishimura et al., 2005), the Montserrat 1997 and 2003 eruptions (Pelinovsky et al., 2004; Mattioli et al., 2007), and the Stromboli 2019 eruption. Despite this, the prediction of wave features in relation to pyroclastic flow conditions is poorly constrained due to a lack of knowledge on the dynamics of pyroclastic flows and their interaction with water. Moreover, experimental, numerical, and theoretical studies, which consider the specific case of pyroclastic flows entering water, are limited and rarely focused on the wave generation. For instance, Freundt (2003) and Allen et al. (2012) investigated experimentally the emplacements and deposits of hot volcanic tephra flows entering water, while Watts and Waythomas (2003) proposed a theoretical analysis on tsunami features generated by pyroclastic density currents by taking into account both the upper dilute suspension and basal dense flow. Finally, these works mainly addressed thermal effects, disregarding the high pore fluid pressure of such flows raised in this study.

The present study aims to investigate the generation of tsunamis by pyroclastic flows during explosive volcanic eruptions. In this objective, novel laboratory experiments of fluidized granular flows entering water are addressed. This simplified configuration ensures a suitable modeling of concentrated pyroclastic flows reaching the sea, considering both the high mobility and the interstitial gas pore pressure of these flows. The present work focuses on the characterization of the leading and largest wave by varying the mass flux per width $q_{m}$ and the volume per width $v$ of the granular flow, the maximum water depth $H_{o}$, and the slope angle $\theta$ of the inclined plane. The paper is organized as follows. In section 2 , earlier works on this issue are presented. Then, the experimental setup is described (section 3). In section 4, preliminary observations of a fluidized granular flow entering water are reported and the control parameters are discussed. Finally, the leading wave is analyzed in terms of different parameters (section 5) and a comparison between fluidized granular, dry (nonfluidized) granular, and water flows entering water is done (section 6).

\section{Earlier works}

To improve the understanding of tsunamis induced by the impact of a subaerial flow, several canonical configurations have been investigated through theoretical models, laboratory experiments, and numerical simulations. Overall, two specific configurations can be distinguished, namely, the entrance of a solid block (piston model, block falling vertically or sliding down an inclined plane) or of a fluid-like material (Newtonian fluid, granular mass, grain-liquid mixture) into water. In the following, earlier studies considering a mass initially above the water surface will be presented and other configurations of fully or partially immersed slides will be disregarded (see Løvholt et al., 2015; YavariRamshe \& Ataie-Ashtiani, 2016, and references herein for more details).

Early studies focused on the most simplified configuration of a solid block impacting water. Depending on initial conditions, a wide range of wave types were observed, such as Stokes waves, cnoidal waves, solitary waves, and bores (e.g., Heinrich, 1992; Heller \& Spinneken, 2015). A classification has been proposed using the wave features (Le Méhauté, 1976) or the slide parameters (Fritz et al., 2004; Heller \& Hager, 2011; Heller \& Spinneken, 2015). In the case of a 2D geometry, the leading wave is usually the most significant wave containing the major part of the energy transferred at the impact, which could 
be then affected by the dispersion (Law \& Brebner, 1968). Its features depend on the impact velocity, the geometry and mass of the slide block, the inclination angle of the plane, and the water depth (Law \& Brebner, 1968; Kamphuis \& Bowering, 1970; Monaghan et al., 2003; Walder et al., 2003; Viroulet et al., 2013). However, the modeling of tsunamis by solid blocks in the context of waves triggered by granular flows has important limitations (Heller \& Kinnear, 2010; Yavari-Ramshe \& Ataie-Ashtiani, 2016). For example, the deformation and the permeability of the granular material could affect the wave characteristics (Lindstrøm, 2016). Usually, the amplitude and the period of the leading wave are reduced and increased, respectively, for granular materials compared to solid blocks with the same initial conditions (Ataie-Ashtiani \& Nik-Khah, 2008; Heller \& Kinnear, 2010).

A more realistic modelling of natural granular flows is the release of a granular mass on an inclined plane. In this case, dimensionless parameters governing the generation of waves are the Froude number $F r=u_{s} /\left(g H_{o}\right)^{1 / 2}$, the relative slide thickness $S=$ $h_{s} / H_{o}$, and the relative slide mass $M=\rho v / \rho_{f} H_{o}^{2}$, where $u_{s}, h_{s}, \rho$, and $v$ are the velocity, the thickness, the bulk density, and the volume per width (i.e., the area orthogonal to the spanwise direction) of the granular flow, $\rho_{f}$ is the water density, $H_{o}$ is the maximum water depth, and $g$ is the gravitational acceleration. Depending on $\mathrm{Fr}$ and $S$, Fritz et al. (2003b) reported different dynamics of the granular flow and of the leading wave at the impact. For large $F r$ and $S$, the water was ejected upward forming an air cavity behind the flow front. In contrast, for lower $F r$ and $S$, the height profile was shaped by water. Moreover, Fritz et al. (2004) reported an empirical equation depending on both $\mathrm{Fr}$ and $S$ to predict the maximum amplitude of the generated wave. Zweifel et al. (2006) gave an empirical relation including the relative mass $M$ in addition to the Froude number $F r$ and the relative slide thickness S. Finally, Heller and Hager (2010) proposed an empirical impulse product parameter to predict the wave characteristics (e.g., amplitude, height, wavelength, and period) as

$$
P=F r S^{1 / 2} M^{1 / 4} \cos ^{1 / 2}\left(\frac{6 \theta}{7}\right)
$$

which is related to the streamwise slide momentum flux component. In the three-dimensional configuration, it has been supported that the Froude number is also the dominant dimensionless parameter in the wave generation (Mohammed \& Fritz, 2012). However, the use of $P$ led to an important inaccuracy on the wave features, used in the case of negatively buoyant granular flows (Heller \& Hager, 2010; Miller et al., 2017), positively buoyant granular flows (Zitti et al., 2016), and water flows (Bullard, Mulligan, Carreira, \& Take, 2019). For example, Heller and Hager (2010) concluded to an inaccuracy up to $\pm 30 \%$ on the relative maximum amplitude and to $\pm 50 \%$ on the relative wave period.

Although a granular material is relevant for modeling rock avalanches, it is limited in the case of pyroclastic density currents. Indeed, these gravity-driven hot gas-particle flows are usually composed of an upper dilute turbulent suspension, often referred to as pyroclastic surge, and a basal concentrated granular avalanche, called pyroclastic flow (Dufek, 2016). While the dilute region can be modeled as a turbulent gravity current, the basal region is more difficult to describe. In particular, pyroclastic flows commonly travel on gentle slopes over distances of several kilometers to several tens of kilometers at speeds of up to about a hundred kilometers per hour, which set them apart from dry granular flows. Sparks (1976) and Wilson (1980) first proposed that the high mobility of these flows was due to their high interstitial gas pore pressure. The sustained pore pressure, which may arise if the permeability is small owing to large amounts of fine ash, conterbalances the weight of grains and therefore reduces the internal friction. In this context, the fluidization process and related pore pressure effect have been studied intensively (e.g., Roche et al., 2002; Dufek \& Manga, 2008; Girolami et al., 2008; Montserrat et al., 2012; Rowley et al., 2014; Valverde \& Soria-Hoyo, 2015; Chédeville \& Roche, 2014; Chédeville \& Roche, 2018; Breard et al., 2018; Smith et al., 2018; Lube et al., 2019; 
Soria-Hoyo et al., 2019). At the laboratory scale, if the pore pressure is maintained long enough owing to slow pressure diffusion, the dynamics of a fluidized granular flow is similar to that of the well-known dam-break flow of pure fluids for which energy dissipation is weak (Roche et al., 2008). At longer times when pore pressure has diffused, the granular material is defluidized, decelerates, and can stop, at sufficiently low slopes. In this case, the final deposit is elongated with a runout length significantly larger than that of an equivalent dry granular flow (Roche et al., 2011). In the present study, granular flows with sustained high gas pore pressure are considered to ensure the dynamic similarity with natural pyroclastic flows.

\section{Methodology}

\subsection{Experimental setup}

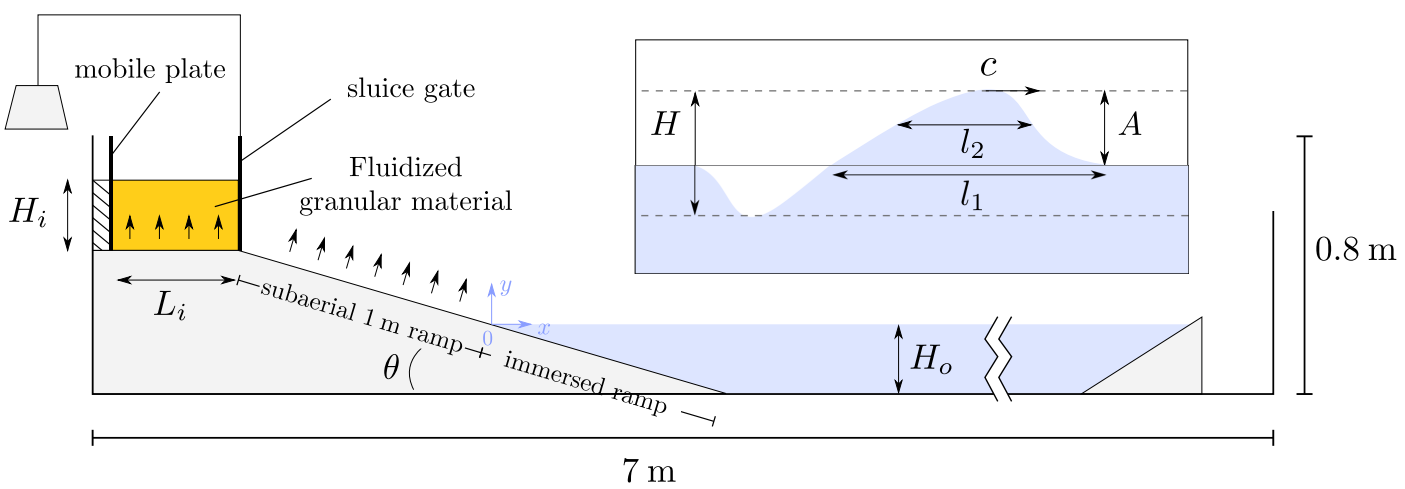

Figure 1. Sketch of the experimental apparatus with the initial parameters (height $H_{i}$ and length $L_{i}$ of the initial column of grains, slope angle $\theta$ and maximum water depth $H_{o}$ ) and the wave features (crest velocity $c$, amplitude $A$, height $H$, crest length $l_{1}$ and half-amplitude length $l_{2}$ ). Black arrows represent the air flux perpendicular to the bottom for the fluidization process.

The experimental setup consists in a horizontal transparent channel of rectangularcross section with dimensions of $7 \mathrm{~m}$ long, $0.8 \mathrm{~m}$ high and $0.2 \mathrm{~m}$ wide along the streamwise $x$, vertical $y$, and spanwise $z$ coordinates, respectively (see Figure 1 ). The origin of the coordinate system $(x, y)$ is located at the shoreline, defined as the position where the undisturbed water surface crosses the inclined plane. On one side, the channel is equipped with a finite volume reservoir delimited by a sluice gate and a mobile vertical plate. The initial column of the flowing material is defined by its length and its height, which are varied in the range $L_{i}=[8.5: 33.8] \pm 0.1 \mathrm{~cm}$ and $H_{i}=[10: 79.5] \pm 0.5 \mathrm{~cm}$, respectively. The reservoir is connected to an inclined plane with a slope angle of $\theta=5^{\circ}, 10^{\circ}$, $15^{\circ}$, or $20^{\circ}$. In this paper, most of the results correspond to experiments performed with $\theta=15^{\circ}$. The inclined plane is splitted into a subaerial $1 \mathrm{~m}$ and an immersed ramp. The latter one ranges from $0.38 \mathrm{~m}$ to $1.5 \mathrm{~m}$, with the maximum water depth varied in the range $H o=[13.1: 38.5] \pm 0.1 \mathrm{~cm}$. Both the reservoir and the subaerial ramp are equipped with a porous plate to fluidize the granular material by an air flux perpendicular to the bottom (see arrows in Figure 1). At the end of the channel, an inclined plate followed by a void volume limits the reflected waves.

At the initial time of the experiment (i.e., $t=0$ ), the sluice gate is removed at about a constant speed of $2 \mathrm{~m} . \mathrm{s}^{-1}$, by releasing a suspended weight. The dynamics of the granular flow and of the disturbed water surface are extracted from image analysis using a classical shadowgraphy method. The free surface is distinguished from the am- 
bient air, by addition of a red dye into water. Two Photron Fastcam $1024 \times 1024$ pixel cameras and LED panels on the opposite side of the channel are used. In the streamwise direction, the two cameras are located at $x=1 \mathrm{~m}$ and $x=2.4 \mathrm{~m}$ from the shoreline, respectively. In the vertical direction, the cameras are located at the same level as the undisturbed initial water surface to prevent image distortion. For the second camera, a light signal turns off at the opening of the sluice gate to determine the initial time. The acquisition rate is $250 \mathrm{~Hz}$ and the spatial resolution is $4 \mathrm{~mm} /$ pixel and $0.8 \mathrm{~mm} /$ pixel, respectively. The high-resolved and more distant camera, for which the field of view is included in that of the large view camera, aims to obtain a better accuracy of wave features. Finally, the extraction process is performed using a Matlab routine, based on a threshold method.

\subsection{Materials}

The granular material used corresponds to monodisperse spherical glass beads manufactured by Wheelabrator. The diameter and density of beads are measured as $d=$ $65 \pm 10 \mu \mathrm{m}$ and $\rho_{p}=2550 \pm 50 \mathrm{~kg} \cdot \mathrm{m}^{-3}$, respectively. The angle of avalanche $\alpha_{a}$ and the angle of repose $\alpha_{r}$ are also estimated from the variations of the slope of an initially horizontal plane granular bed in a transparent box $\left(5 \times 11 \times 18 \mathrm{~cm}^{3}\right)$ which is slowly tilted. The angle of avalanche is the critical angle above which grains spontaneously starts to flow, until the granular material stabilizes at the angle of repose. Here, they are equal to $\alpha_{r}=25 \pm 1^{\circ}$ and $\alpha_{a}=29 \pm 1^{\circ}$, respectively. It can be noted that the slope angle $\theta$ of the inclined plane is always lower than the repose angle $\alpha_{r}$ of the granular material. It means that, for dry (nonfluidized) granular collapses, the mass does not entirely enter water and a final deposit formed on the subaerial ramp, unlike fluidized granular flows (Bougouin et al., 2019). The case of fluidized granular flows allows therefore to investigate lower slope angles with an entire mobility of the granular mass compared to the analogous dry situation. Finally, the initial volume fraction of the granular column is $\phi_{i} \sim$ $0.56 \pm 0.01$.

Some experiments with salt water flows have also been performed, in order to compare the results with fluidized and dry granular flows. In this case, sodium chloride $(\mathrm{NaCl})$ is added in dyed water with a concentration of $325 \mathrm{~g} / \mathrm{kg}$ of water, giving a salt water flow denser than the fresh water in the channel. The obtained density is $\rho=1197 \mathrm{~kg} . \mathrm{m}^{-3}$ measured by a DMA 35 Anton Paar electronic densimeter with an accuracy of $\pm 0.5 \mathrm{~kg} . \mathrm{m}^{-3}$.

\subsection{Laboratory modeling of pyroclastic flows}

In the present study, a specific attention is paid on the modeling of pyroclastic density currents at the laboratory scale. In particular, the basal concentrated flow is only considered here, as it mainly contributes in the wave generation (Watts \& Waythomas, 2003). A suitable modeling of natural pyroclastic flows with large amounts of ash conferring a low material permeability corresponds to fluidized granular flows (Roche, 2012). The fluidization process generates high pore fluid pressure, which reduces the internal friction and therefore promotes the high mobility (e.g., long runout distance). In this study, the minimum fluidization velocity of the granular material is $U_{m f} \sim 3.8 \mathrm{~mm} . \mathrm{s}^{-1}$, estimated as the velocity for which the gas pore pressure counterbalances the pressure of a static granular column. Before each experiment, the granular material is fluidized and the air flow rate is then switched off. This process leads to a dilatation of the granular column, which allows to obtain an equivalent initial volume fraction $\phi_{i} \sim 0.56 \pm 0.01$, for dry and fluidized granular materials. In the latter case, the granular material is refluidized with an air velocity of $U_{f}=4.7 \pm 0.1 \mathrm{~mm} . \mathrm{s}^{-1}$, without significant decompaction, which ensures a fully fluidized flow, that is, $U_{f} / U_{m f} \sim 1.2>1$. Additionally, the pressure diffusion of natural flows is relatively slower than at the laboratory scale essentially because of flow thickness (Rowley et al., 2014; Smith et al., 2018). The granular material is therefore fully fluidized until it reaches water, both in the reservoir and on the sub- 
aerial inclined plane. Note that, other specific features of pyroclastic flows, such as heat transfers, are disregarded (see Freundt, 2003; Allen et al., 2012, for some details on thermal effects).

A posteriori of experiments, the dynamics of fluidized granular flows can be quantified by the flow Froude number defined as $F r^{f}=u_{f} /\left(g h_{f}\right)^{1 / 2}$, where $u_{f}$ and $h_{f}$ are the velocity and the height at the front $\left(u_{f}\right.$ and $h_{f}$ will be defined later in section 4.2). In the present study, this dimensionless parameter is found in the range $F r^{f}=[6: 9]$, which is in the upper range given for natural pyroclastic flows $\mathrm{Fr}^{f}=\left[10^{-1}: 10^{1}\right]$ (Freundt, 2003; Roche, 2012; Delannay et al., 2017). Additionally, the bulk flow to water density ratio $\rho / \rho_{f}$ can be estimated, being an important parameter in the wave generation. In the case of granular flows, the bulk density is defined as $\rho=\phi \rho_{p}+(1-\phi) \rho_{a}$, where $\phi$ is the volume fraction of grains, and $\rho_{p}=2550 \mathrm{~kg} \cdot \mathrm{m}^{-3}$ and $\rho_{a}=1.2 \mathrm{~kg} . \mathrm{m}^{-3}$ are the grain and ambient air densities. In the current setup, the volume fraction $\phi$ at the impact cannot be measured. In our experiments and in the analysis below, it is therefore assumed that the fluidization maintains the volume fraction from the initial state to the impact, $\phi=\phi_{i} \sim 0.56 \pm 0.01$. By contrast, for the dry granular configuration, it is probable that a slight compaction occurs as $\phi \sim 0.58-0.59$, corresponding to the critical volume fraction for which no contraction or dilatation are necessary to flow on gentle slopes (Pouliquen, 1999; Gravish \& Goldman, 2014). The bulk density of fluidized granular flows is therefore equal to $\rho \sim 1400 \mathrm{~kg} . \mathrm{m}^{-3}$, leading to $\rho / \rho_{f} \sim 1.4$ included in the upper range estimated for pyroclastic flows $\rho / \rho_{f}=[0.05: 1.5]$ (Freundt, 2003; Roche, 2012; Delannay et al., 2017). To conclude, the present study mainly focuses on the modeling of the denser and faster pyroclastic flows entering the sea.

\section{Laboratory experiments of a fluidized granular flow into water}

\subsection{Preliminary observations}

In Figure 2, the typical evolution of a fluidized granular flow entering water is shown, at five different times. A movie of the same experiment is also available in the Supporting Information. After the release of the initial column, the fluidized granular material accelerates on the inclined plane until it reaches a constant front-velocity. Then, the granular flow impacts water, leading first to a single vertical granular jet over water (Figure $2 a)$. This behavior has already been reported for the entrance of experimental volcanic ash flows into water (Freundt, 2003), while it has never been observed for coarse grains $d>\mathcal{O}\left(10^{-3}\right) \mathrm{m}$ (Fritz et al., 2003a; Viroulet et al., 2014; Miller et al., 2017). The vertical jet is also obtained in the case of salt water flows impacting water. Simultaneously, the granular material pushes water, and it generates a large-amplitude wave, which can be followed by low-amplitude waves. The wave breaks quickly after the impact, and grains, previously ejected by the initial jet, fall onto it. The grains are mixed and partially transported by the breaking wave before they settle into water (Figures $2 \mathrm{~b}$ and $2 \mathrm{c}$ ). Surprisingly, the amplitude $A$ of the leading and largest wave is much larger than the flow thickness $h_{f}\left(A / h_{f} \sim 8\right.$ for this experiment). Additionally, the entrance of the granular material into water leads to a turbulent mixing zone with a roughly linear interface to clear water (Figure 2b). Then, a turbidity current emerges from the mixing zone on the immersed inclined plane (Figure 2c). Indeed, this current behaves like a particle-laden gravity current in which grains are mainly suspended by the turbulent fluid (e.g., Kneller \& Buckee, 2000). At early times of its propagation, a lot of bubbles, originating probably to the interstitial gas of the flow, are released. The turbidity current propagates until the end of the channel (Figures $2 \mathrm{~d}$ and $2 \mathrm{e}$ ). In the range of parameters considered, the wave velocity is always faster than that of the turbidity current, with about a factor 4 . Finally, a thick granular deposit is obtained at the end of the immersed inclined plane (not shown here), which suggests a significant settling of particles at the impact. Note that the flow dynamics and the final deposit of the granular material beneath the water surface are disregarded in the present study. 


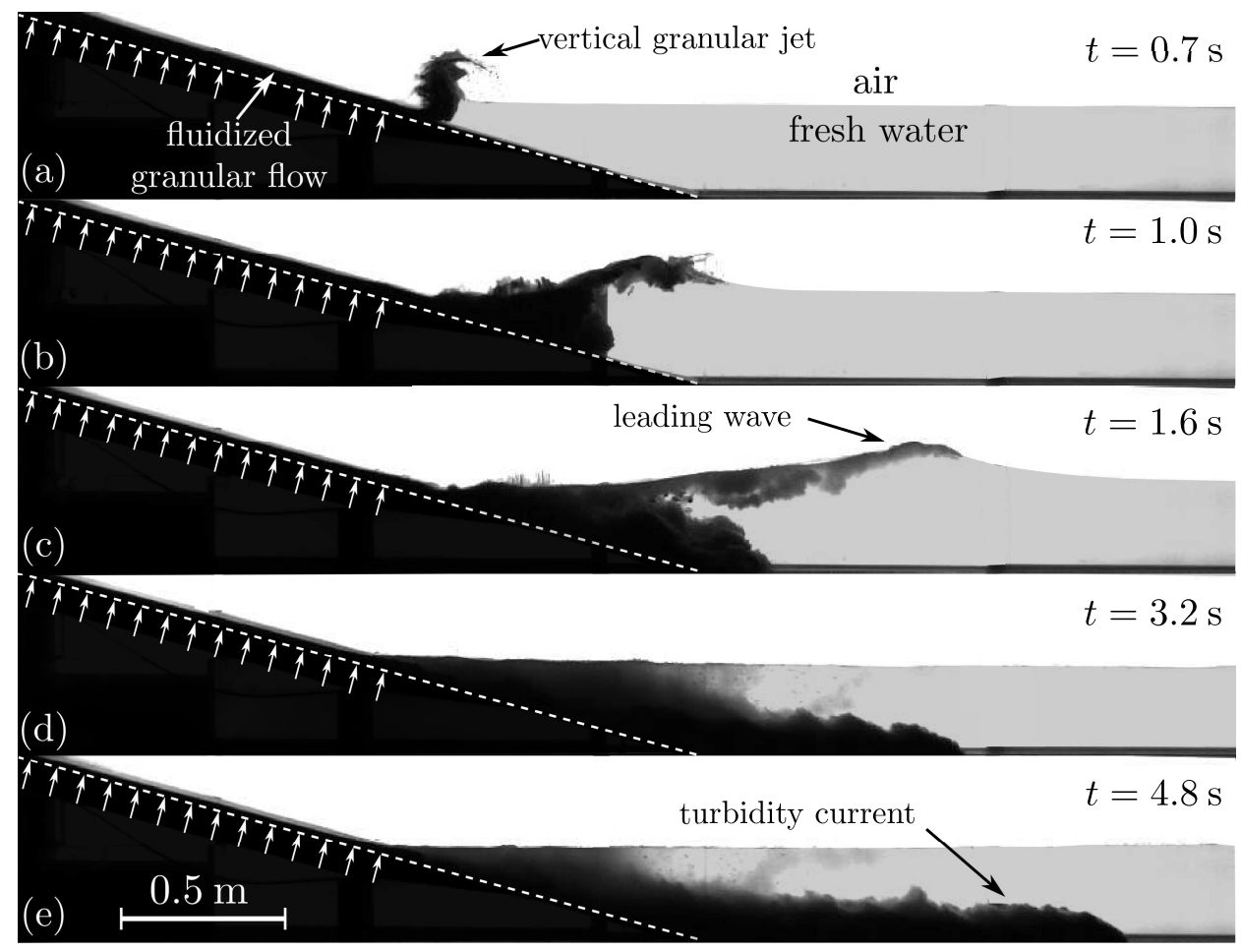

Figure 2. Snapshots of a fluidized granular flow entering water, at five different times, after gate opening at $t=0$. The initial conditions are $H_{i}=21.5 \mathrm{~cm}, L_{i}=33.8 \mathrm{~cm}, \theta=15^{\circ}$, and $H_{o}=26.5 \mathrm{~cm}$. White arrows represent the air flux perpendicular to the inclined plane for the fluidization process.

\subsection{Control parameters}

In view of these preliminary observations and of earlier works, it is relevant to define the control parameters at the impact. In particular, the fluidized granular flow can be characterized by its constant front-velocity $u_{f}$ and its front-height $h_{f}$, its volume per width $v$ and its bulk flow density $\rho$. As discussed in section 3.3, the bulk flow density, defined as $\rho=\phi_{i} \rho_{p}+\left(1-\phi_{i}\right) \rho_{a}$, is roughly constant in the set of experiments. However, the volume per width $v$ is dependent on the characteristic lengths of the initial column, while the dependency of $u_{f}$ and $h_{f}$ on initial parameters is not trivial. In the Supporting Information, a summary table of control parameters is provided (Table S1).

Figure 3 presents (a) the constant flow front-velocity $u_{f}$ and (b) the front-height $h_{f}$ at the impact, as a function of the initial height $H_{i}$ of the granular column, with $\theta=$ $15^{\circ}$. In this study, the front-height $h_{f}$ is defined as the flow height at $10 \mathrm{~cm}$ behind the front to prevent the important gradient of the height profile, while remaining relatively close to the front (more details are provided in the Supporting Information). Moreover, the length of the initial column varies here, but no effect on $u_{f}$ and on $h_{f}$ has been observed. Indeed, it has already been reported that $u_{f}$ is mostly controlled by the initial height $H_{i}$ of the column in the case of dry granular collapses over inclined planes (Farin et al., 2014) and of fluidized granular flows on horizontal planes (Roche et al., 2008). Finally, the lower and upper horizontal error bars correspond to the values of $H_{i}-h_{r}$ and $H_{i}$, respectively, where $h_{r} \sim 3 \mathrm{~cm}$ is the height of the granular mass remaining in the reservoir at the end of the experiment. 

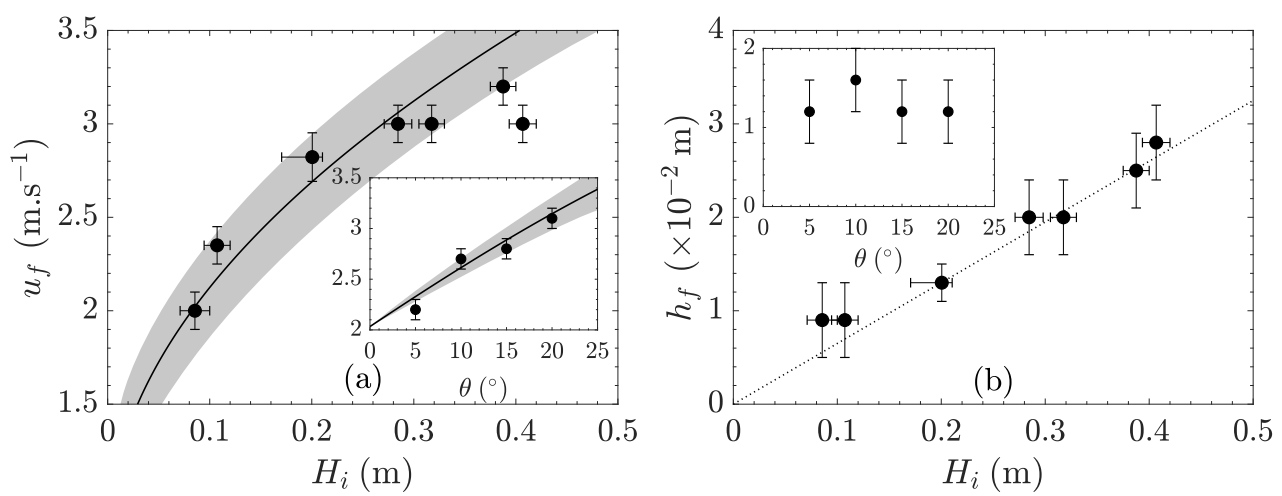

Figure 3. (a) Constant flow front-velocity $u_{f}$ and (b) front-height $h_{f}$ at the impact, as a function of the initial height $H_{i}$ of the granular column, with $\theta=15^{\circ}$. The insets represent $u_{f}$ and $h_{f}$ as a function of the slope angle $\theta$, with $H_{i}=21.5 \mathrm{~cm}$ and $L_{i}=33.8 \mathrm{~cm}$. (-) Equation (2) with $\beta=1.4$ and $t=T=0.3 \mathrm{~s}$ (inset: $t=T=0.35 \mathrm{~s}$ ), where $T$ is the flow time to reach the constant-front velocity $u_{f}$ after the experiments. The gray area shows the scatter of $T$ in the range $\pm 0.1 \mathrm{~s}$ (inset: $\pm 0.05 \mathrm{~s}$ ). $(\cdots) h_{f}^{(s)} / H_{i}=6.5 \%$.

Both the constant-front velocity $u_{f}$ (Figure 3a) and the front-height $h_{f}$ (Figure $3 \mathrm{~b}$ ) are shown to increase for increasing $H_{i}$. For $H_{i}>0.25 \mathrm{~m}$, it seems that $u_{f}$ becomes constant, but there is no physical explanation and further experiments will therefore be necessary to support this trend. The front-height $h_{f}$ evolves linearly with $H_{i}$, with in particular $h_{f}^{(s)} / H_{i}=6.5 \%$ (dotted line, in Figure $3 \mathrm{~b}$ ). Additionally, the insets show $u_{f}$ and $h_{f}$ as a function of the slope angle $\theta$, for $H_{i}=21.5 \mathrm{~cm}$ and $L_{i}=33.8 \mathrm{~cm}$. The front-velocity $u_{f}$ increases for increasing $\theta$, similar to granular collapses over inclined planes (Mangeney et al., 2010). In contrast, the front-height $h_{f}$ is not affected by the slope angle $\theta$ and a constant mean value $h_{f} \sim 1.2 \mathrm{~cm}$ is obtained here.

For a sudden release of a finite volume of frictionless fluid down an inclined plane, well-known as the dam-break problem, shallow-water equations can be used to predict the flow front-velocity (Ancey et al., 2008, and references herein). It is obtained

$$
u_{f}^{t h}=\beta \sqrt{g H_{i} \cos \theta}+g t \sin \theta,
$$

where the constant parameter $\beta=2$ theoretically. In the horizontal case (i.e., $\theta=0^{\circ}$ ), the Ritter analytical solution is also recovered, which predicts a constant front-velocity $u_{f}^{\text {th }}=2 \sqrt{g H_{i}}$ for a semi-infinite volume (Ritter, 1892). For the inclined configuration, equation (2) predicts a constant acceleration of the flow as $d u_{f}^{t h} / d t=g \sin \theta$. In our experiments, acceleration is only observed up to $t=T \sim 0.3 \pm 0.1$, above which the frontvelocity becomes constant. This difference could be attributed to the hypothesis of the model, in particular, that the solid bottom and wall friction are neglected. In the following, it is assumed that equation (2) is applicable up to $t=T$, and the constant frontvelocity $u_{f}$ can be estimated, at $t=T$, with $\beta$ a fitting parameter.

In Figure 3a, the solid line represents the analytical solution of dam-break flows over an inclined plane $u_{f}^{\text {th }}$ (equation (2)) with $\beta=1.4$ and $t=T=0.3 \mathrm{~s}$. The gray area indicates the scatter of $T$ in the range $\pm 0.1 \mathrm{~s}$, after the experiments. The general trend of both the analytical solution and the experimental data are in good agreement. Additionally, in the case of dam-break flows on a horizontal plane, it is well known that a value of $\beta=2$ is hardly reached due to bottom shear dissipation, which becomes significant in regions where the depth of the current becomes small, particularly close to the front (Dressler, 1952; Hogg \& Woods, 2001; Hogg \& Pritchard, 2004). In the liter- 
ature, the parameter $\beta$ is usually found in the range $\beta=[1: 2]$ (Dressler, 1954; Jánosi et al., 2004; Leal et al., 2006; Roche et al., 2008; Bonometti et al., 2008; Bougouin et al., 2017 ), according to the value $\beta=1.4$ obtained here. Similar conclusions can be drawn from the inset of Figure 3a. The experimental data and equation (2), with $\beta=1.4$ and $t=T=0.35 \pm 0.05 \mathrm{~s}$, match very well together.

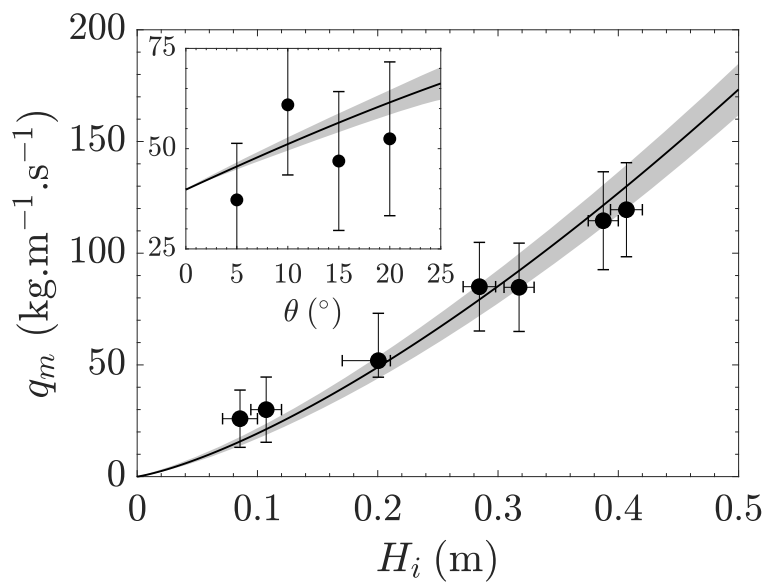

Figure 4. Mass flux per width $q_{m}=\rho u_{f} h_{f}$ at the impact, as a function of the initial height $H_{i}$ of the granular column, with $\theta=15^{\circ}$. The inset shows $q_{m}$ as a function of the slope angle $\theta$, with $H_{i}=21.5 \mathrm{~cm}$ and $L_{i}=33.8 \mathrm{~cm}$. (-) predictive model $q_{m}^{(s)}=\rho u_{f}^{t h} h_{f}^{(s)}$, where $\rho=1400$ kg.m ${ }^{-3}, u_{f}^{t h}$ defined by equation (2) with $\beta=1.4$ and $t=T=0.3 \mathrm{~s}$ (inset: $t=T=0.35$ $\mathrm{s}$ ), and $h_{f}^{(s)} / H_{i}=6.5 \%$ (dotted line, in Figure $3 \mathrm{~b}$ ). The gray area shows the scatter of $T$ in the range $\pm 0.1 \mathrm{~s}$ (inset: $\pm 0.05 \mathrm{~s}$ ).

For $\theta$ fixed, the constant flow front-velocity $u_{f}$ and the front-height $h_{f}$ increase together for increasing $H_{i}$. Thus, it is not possible to vary these two parameters independently. In this way, the mass flux per width $q_{m}=\rho u_{f} h_{f}$ is defined, including both the velocity $u_{f}$ and the height $h_{f}$ of the granular flow. As expected, $q_{m}$ increases for increasing $H_{i}$ and $\theta$, as shown in Figure 4 . In the latter case, the increase of $q_{m}$ is only due to the $\theta$-dependency of $u_{f}$, while $h_{f}$ is not affected. Moreover, the predictive model $q_{m}^{(s)}=$ $\rho u_{f}^{t h} h_{f}^{(s)}$ (solid line and gray area) is in fairly good agreement with the experimental data with a similar trend.

\section{Characterization of the leading wave}

In this section, the leading and largest wave features are analyzed in light of the mass flux per width $q_{m}=\rho u_{f} h_{f}$ and the volume per width $v=\left(H_{i}-h_{r}\right) L_{i}$ of the granular flow, with $h_{r} \sim 3 \mathrm{~cm}$ the height of the granular mass remaining into the reservoir at the end of the experiment, and the maximum water depth $H_{o}$. The wave is defined by its amplitude $A$, its height $H$, its crest length $l_{1}$, its half-amplitude length $l_{2}$, and its crest velocity $c$ (see Figure 1). Note that the amplitude of the leading and largest wave at $x=2,2.4$ and $2.8 \mathrm{~m}$ from the shoreline, is provided in the summary table in the Supporting Information (Table S1).

\subsection{Wave types}

Figure 5 presents a diagram of wave types in the $\left(H_{o} / g T^{2}, H / g T^{2}\right)$ plane, based on Le Méhauté (1976). In particular, regions of linear, Stokes, and cnoidal waves are in- 
dicated with colored areas. Experimental data of the present study are also represented, corresponding to the wave features at $x=2 \mathrm{~m}$ (circles), $x=2.4 \mathrm{~m}$ (squares) and $x=$ $2.8 \mathrm{~m}$ (diamonds) from the shoreline. The period of the leading wave is defined as $T=$ $2 l_{1} / c$.

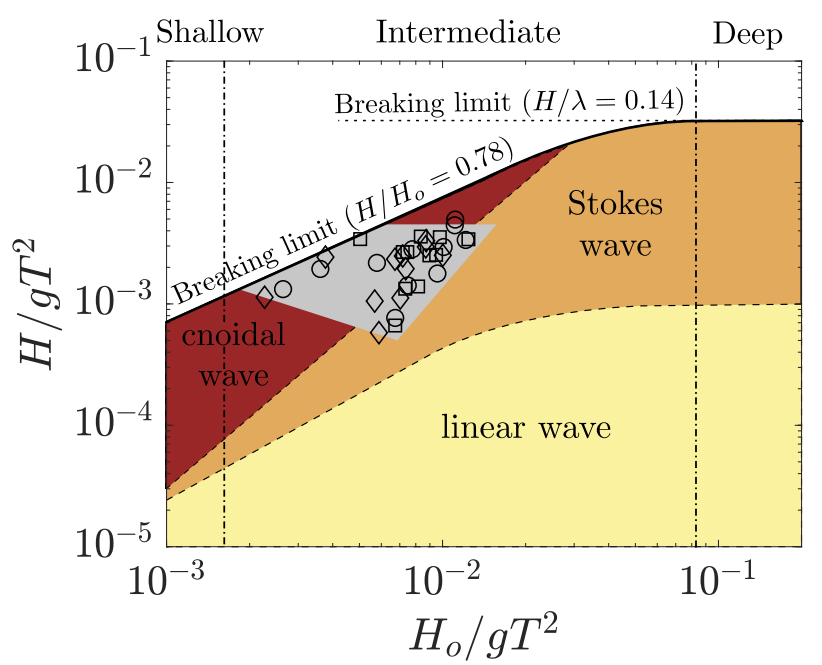

Figure 5. Diagram of wave types in the $\left(H_{o} / g T^{2}, \quad H / g T^{2}\right)$ plane, based on Le Méhauté (1976). Experimental data of the present study are also represented with $T=2 l_{1} / c$ the period of the leading and largest wave, at $x=2 \mathrm{~m}$ (circles), $x=2.4 \mathrm{~m}$ (squares) and $x=2.8 \mathrm{~m}$ (diamonds) from the shoreline. Gray area represents the range of the experiments performed in this study.

The diagram is limited by a breaking criterion above which wave breaking occurs (solid line in Figure 5). In shallow and deep water conditions, this criterion reduces to $H / H_{o}=0.78$ (McCowan, 1894) and $H / \lambda=0.14$ (Michell, 1893), respectively. In the present study, all experiments are below the breaking criterion, which suggests that most of leading waves have probably already broken. Note that wave breaking is expected to occur for lower $H / H_{o}$, given that the wave generation takes part in the shallow region of the inclined plane (more discussed in section 5.3). Secondly, all experiments performed here corresponds to Stokes and cnoidal wave types, while some data are broadly close to the Stokes-cnoidal transition. The diagram provides merely a qualitative representation of wave type regions and caution must be exercised with these transitions. Finally, all experiments correspond to the intermediate water depth conditions, similar to waves generated by a pneumatic granular flow generator (Fritz et al., 2004). Remind that robust wave theories are mainly available for linear waves, for Stokes waves in deep water, and for cnoidal waves in shallow water, under steady-state conditions. In our case, there are therefore no applicable water wave theories.

\subsection{Role of the granular flow: mass flux and volume}

Figure 6 presents the temporal evolution of the water height profile $\eta$ for different mass fluxes per width $q_{m}$ and different volumes per width $v$ of the granular flow. More specifically, the influence of $q_{m}$ (Figures 6a and 6b) and $v$ (Figures 6c and 6d) on the leading and largest wave is shown, while other parameters are kept constant.

No perturbation is observed as long as the leading wave has not reached the most proximal wave gauge location, at $t \sim 1.5 \mathrm{~s}$. For $t \gtrsim 1.5 \mathrm{~s}$, the water surface is disturbed with a first positive crest which is also the largest one. At low $q_{m}$ and $v$ (Figures 6 a and 
(a) low $q_{m}$

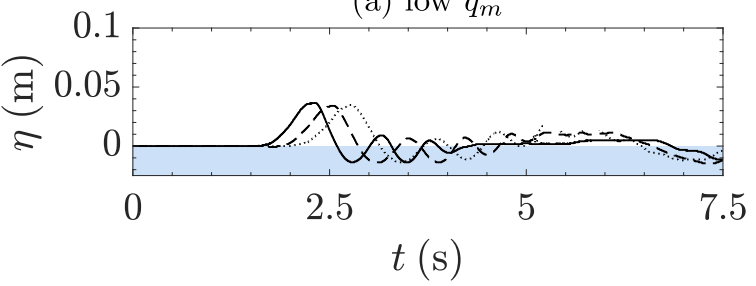

(c) low $v$

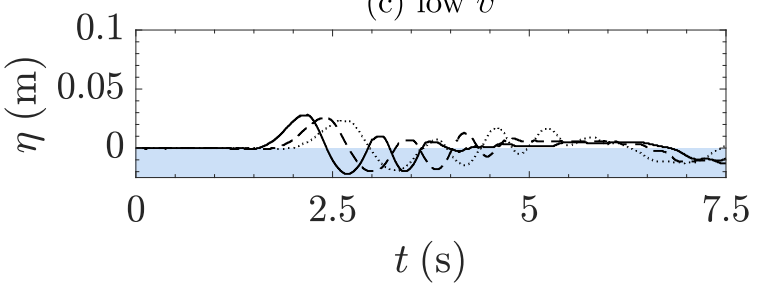

(b) high $q_{m}$

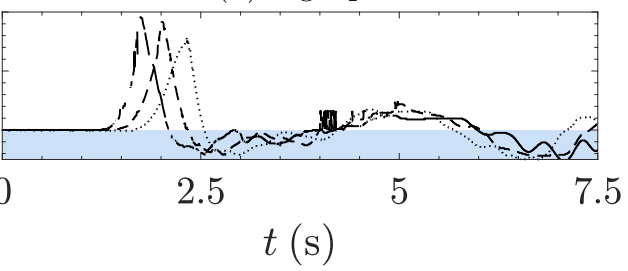

(d) high $v$

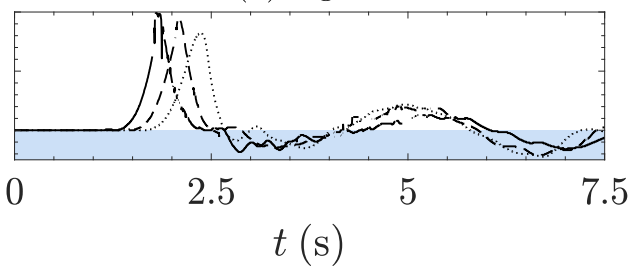

Figure 6. Temporal evolution of the water height profile $\eta$ for (a) $q_{m}=30 \mathrm{~kg} \cdot \mathrm{m}^{-1} \cdot \mathrm{s}^{-1}, v=$ $3.1 \mathrm{dm}^{2}$, (b) $q_{m}=115 \mathrm{~kg} \cdot \mathrm{m}^{-1} \cdot \mathrm{s}^{-1}, v=3.1 \mathrm{dm}^{2}$, (c) $q_{m}=45 \mathrm{~kg} \cdot \mathrm{m}^{-1} \cdot \mathrm{s}^{-1}, v=1.5 \mathrm{dm}^{2}$, and (d) $q_{m}=47 \mathrm{~kg} \cdot \mathrm{m}^{-1} \cdot \mathrm{s}^{-1}, v=6.3 \mathrm{dm}^{2}$, at $(-) x=2 \mathrm{~m},(--) x=2.4 \mathrm{~m}$ and $(\cdots) x=2.8 \mathrm{~m}$ from the shoreline, with $\theta=15^{\circ}$ and $H_{o}=26.5 \mathrm{~cm}$.

6c), the leading wave is followed by low-amplitude waves, while only a single large-amplitude wave is obtained at large $q_{m}$ and $v$ (Figures $6 \mathrm{~b}$ and $6 \mathrm{~d}$ ). Note that, in Figures $6 \mathrm{~b}$ and $6 \mathrm{~d}$, the elevation of the free-surface, at $t \sim 5 \mathrm{~s}$, is attributed to a part of the leading wave reflected by the wave breaker. Moreover, the effect of $q_{m}$ and of $v$ on the water surface is very similar. At low $q_{m}$ and $v$, the leading and largest wave is smooth and slightly nonlinear with a moderate amplitude $A \sim 3.5 \mathrm{~cm}$ (Figure 6a) and $A \sim 2.3-2.8 \mathrm{~cm}$ (Figure 6c). By contrast, at large $q_{m}$ and $v$, the wave is strongly nonlinear with a trough much smaller than the steep crest. The wave amplitude is larger than at low $q_{m}$ and $v$, with in particular, $A \sim 7.9-9.6 \mathrm{~cm}$ (Figure 6b) and $A \sim 8.1-10.0 \mathrm{~cm}$ (Figure 6d). In both cases, the amplitude $A$ decreases during the wave propagation from $x=2 \mathrm{~m}$ to $x=2.8 \mathrm{~m}$ from the shoreline.

Figure 7 shows (a,b) the amplitude $A$ and (c,d) the crest length $l_{1}$ of the leading and largest wave as a function of (a,c) the mass flux per width $q_{m}$ and $(\mathrm{b}, \mathrm{d})$ the volume per width $v$ of the granular flow, at three different positions from the shoreline. As expected, the wave amplitude $A$ increases for increasing $q_{m}$ and $v$ (Figure $7 \mathrm{a}$ and $7 \mathrm{~b}$ ). In particular, $A$ increases by a factor 2.5 and 3.5 when $q_{m}$ and $v$ are increased by a factor 4 , respectively. Similar conclusions can be drawn from the evolution of the wave height $H$ with $q_{m}$ and $v$ (insets of Figures $7 \mathrm{a}$ and $7 \mathrm{~b}$ ). The influence of $q_{m}$ and $v$ on the wave amplitude are therefore of the same order of magnitude. Additionally, $H$ seems to reach a constant value $H \sim 0.1 \mathrm{~m}$, for $v \gtrsim 4.7 \mathrm{dm}^{2}$ (inset of Figure $7 \mathrm{~b}$ ). It suggests that, at sufficiently large $v$, the volume of the granular flow should not affect the wave generation. More specifically, if the flow duration is much longer than the wave generation, it is expected that the finite volume does not play a role on the wave features, and the problem can be related to an infinite volume entering water. In our experiments, the wave features are still affected by the granular volume per width $v$, knowing that the generation occurs in less than $0.5 \mathrm{~s}$, as discussed later in section 5.3. Finally, the amplitude $A$ is shown to decrease significantly during the propagation of the leading wave, from $x=2 \mathrm{~m}$ (solid lines with circles) to $x=2.8 \mathrm{~m}$ (dotted lines with diamonds) from the shoreline. This decrease is much less pronounced for the wave height $H$. During the wave 

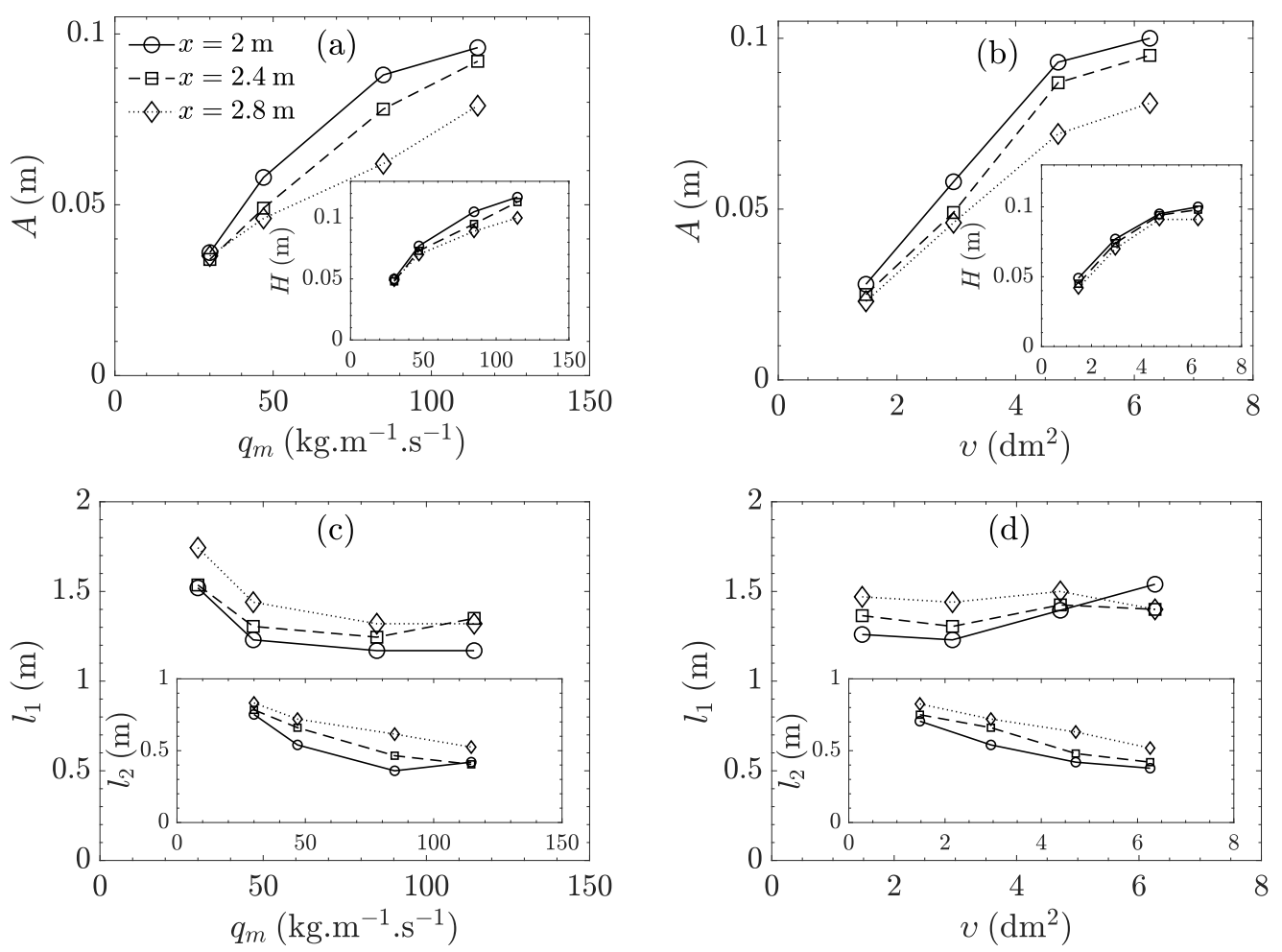

Figure 7. (a,b) Wave amplitude $A$ (inset: wave height $H$ ) and (c,d) crest length $l_{1}$ (inset: half-amplitude length $\left.l_{2}\right)$ as a function of (a,c) the mass flux per width $q_{m}\left(v \sim 3.1 \mathrm{dm}^{2}\right)$ and (b,d) the volume per width $v\left(q_{m} \sim 46 \mathrm{~kg} \cdot \mathrm{m}^{-1} \cdot \mathrm{s}^{-1}\right)$, at $x=2 \mathrm{~m}, x=2.4 \mathrm{~m}$, and $x=2.8 \mathrm{~m}$ from the shoreline, with $\theta=15^{\circ}$ and $H_{o}=26.5 \mathrm{~cm}$.

propagation, the strong decrease of $A$ is therefore associated to an increase of the wave trough, to explain the low decrease of $H$.

While the amplitude $A$ and the height $H$ represent the characteristic dimensions of the wave in the vertical direction, the crest length $l_{1}$ and the half-amplitude length $l_{2}$ correspond to those in the horizontal direction. Overall, the crest length $l_{1}$ varies slightly with $q_{m}$ and $v$, in the range of parameters considered (Figures $7 \mathrm{c}$ and $7 \mathrm{~d}$ ). Except for $q_{m} \sim 30 \mathrm{~kg} \cdot \mathrm{m}^{-1} \cdot \mathrm{s}^{-1}, l_{1}$ is roughly constant and equal to $l_{1} \sim 1.2-1.4 \mathrm{~m}$. By contrast, the half-amplitude length $l_{2}$ decreases for increasing $q_{m}$ and $v$ (insets of Figures $7 \mathrm{c}$ and $7 \mathrm{~d}$ ). In particular, $l_{2}$ decreases roughly by a factor 2 when both $q_{m}$ and $v$ are increased by a factor 4 . It can be concluded that, for increasing $q_{m}$ and $v$, the amplitude $A$ and the half-amplitude length $l_{2}$ increases and decreases, respectively, leading to steeper leading waves. Finally, both lengths $l_{1}$ and $l_{2}$ increase during the wave propagation from $x=2 \mathrm{~m}$ (solid lines with circles) to $x=2.8 \mathrm{~m}$ (dotted lines with diamonds), in agreement with the decrease of the wave amplitude $A$, by mass conservation.

\subsection{Role of the maximum water depth}

At $x=2 \mathrm{~m}$ to $x=2.8 \mathrm{~m}$ from the shoreline, it has been previously shown that the wave types obtained correspond to Stokes and cnoidal waves in the intermediate water depth conditions. It is therefore probable that the maximum water depth $H_{o}$ affects the generation and the propagation of the leading and largest wave. Up to $x / l_{1} \sim 2$ 
from the shoreline, its influence is now investigated while other control parameters are kept constant.
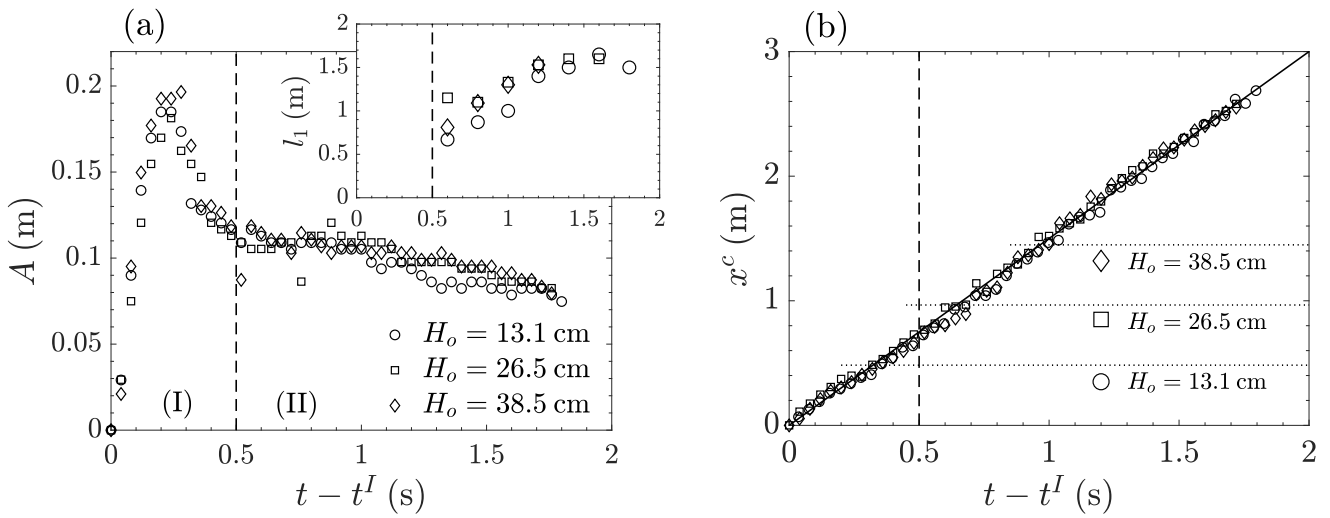

Figure 8. (a) Amplitude $A$ (inset: crest length $l_{1}$ ) and (b) horizontal position of the crest $x^{c}$ as a function of $t-t^{I}$, with $t^{I}$ the time at which the granular flow impacts water, for different maximum water depths $H_{o}$. The other parameters are $q_{m} \sim 47 \mathrm{~kg} \cdot \mathrm{m}^{-1} \cdot \mathrm{s}^{-1}, v \sim 6.4 \mathrm{dm}^{2}$ and $\theta=15^{\circ}$. (- - ) delimits $(I)$ the generation of the vertical granular jet, and $(I I)$ the propagation of the leading and largest wave. In (b), $(-) c=d x^{c} / d t=1.5 \mathrm{~m} \cdot \mathrm{s}^{-1} ;(\cdots)$ position of the slope break depending on $H_{o}$.

Figure $8(\mathrm{a})$ shows the temporal evolution of the amplitude $A$ for different maximum water depths $H_{o}$. First, the temporal evolution of $A$ is similar for the three different water depths considered. In particular, two distinct phases can be distinguished. Stage $(I)$ corresponds to the generation of the vertical granular jet by the impact of the flow into water. Note that, during this stage, the amplitude $A$ corresponds to the maximum elevation of the granular jet, and it does not represent the wave amplitude. The granular jet elevates until it reaches a height of about $0.2 \mathrm{~m}$ and then it falls back on the leading wave. Even if we do not have access to the growth of the leading and largest wave close to the impact, it can be concluded that the maximum wave amplitude is reached in a short time lower than $0.5 \mathrm{~s}$ after the impact, in agreement with previous works (Heller et al., 2016; Clous \& Abadie, 2019; Bullard, Mulligan, Carreira, \& Take, 2019). Stage (II) corresponds to the wave propagation for which the amplitude $A$ and the crest length $l_{1}$ (inset of Figure 8a) decreases and increases, respectively. Up to $t-t^{I} \sim 1.8 \mathrm{~s}$, with $t^{I}$ the time at which the granular flow impacts water, the temporal evolution of the length scales of the wave is independent on $H_{o}$.

Figure 8(b) shows the temporal evolution of the horizontal position of the wave crest, defined as $x^{c}=x(y=A)$, for different maximum water depths $H_{o}$. The dotted lines indicate the location of the slope break, at the transition from the immersed inclined plane to the horizontal bottom, depending on $H_{o}$. Once again, the propagation of the wave crest is independent on $H_{o}$, and in particular, the crest position evolves linearly with the time meaning a constant crest velocity. More specifically, it is found $c=d x^{c} / d t=1.5$ $\mathrm{m} . \mathrm{s}^{-1}$ (solid line). Unfortunately, no correlation is obtained with different control parameters of the flow and further work will be necessary. For all experiments in the present study, the crest velocity is roughly constant and equal to $c \sim 1.5 \pm 0.3 \mathrm{~m} . \mathrm{s}^{-1}$. For comparison, the typical velocity of small-amplitude waves in shallow water gives $\sqrt{g H_{o}}=$ $[1.1: 1.9] \mathrm{m} . \mathrm{s}^{-1}$ in the range of maximum water depths considered here. In the limit of our experimental conditions, this relation gives a fairly good estimate of the crest velocity, despite the crude assumptions. 
In the near-field region, the independency of the generation and of the propagation of the leading and largest wave on the maximum water depth $H_{o}$ can be explained as follows. The impact of a fluidized granular flow into water generates a wave in a short time, less than $0.5 \mathrm{~s}$ as discussed previously. Moreover, the wave generation mainly occurs on the immersed inclined plane so that the maximum water depth, far away from the shoreline, can therefore be first disregarded. It is important to recall that the $H_{o}$ independency of wave features is observed in the near-field region, at least up to $x / l_{1} \sim$ 2 from the shoreline. At sufficiently long times and far enough from the shoreline, it is expected that the $H_{o}$ dependency of the wave will be recovered, as already shown in the case of water flows entering water (Bullard, Mulligan, Carreira, \& Take, 2019; Bullard, Mulligan, \& Take, 2019). However, the distance required is probably too large with respect to the dimensions of our experimental setup to observe this near- to far-field transition, in the range of parameters considered here.

\section{Comparison with dry granular and water flows}

In the previous sections, it has been shown that, in the near-field region, the wave features are mostly controlled by the mass flux $q_{m}$ and the volume $v$ of the fluidized granular flow, while the maximum water depth $H_{o}$ can be disregarded. In this way, the questions raised are the following. Does the nature of the flowing material affect the wave features? Are there differences between dry (nonfluidized) granular flows, fluidized granular flows or water flows in the wave generation?

\subsection{Flow dynamics at the impact}
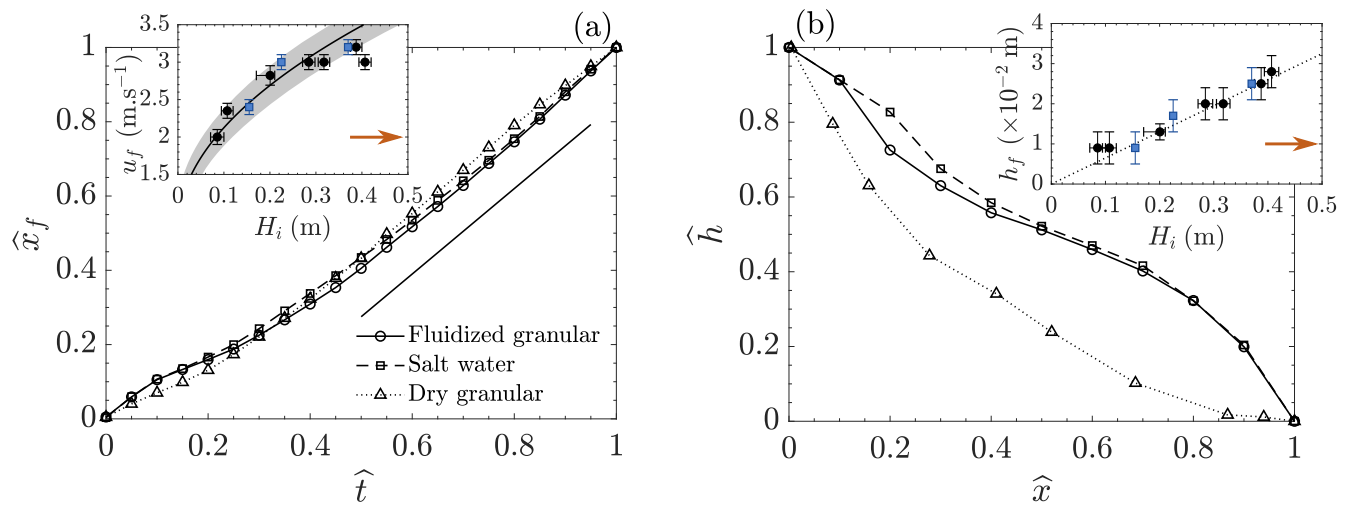

Figure 9. (a) Temporal evolution of the front position $\widehat{x}_{f}$ and (b) typical height profile $\widehat{h}$ at the impact, for fluidized granular, dry granular, and salt water flows, in a dimensionless form (equation (3)). In (a), (-) $\widehat{x}_{f}=1.15 \widehat{t}$. Insets: (a) constant flow front-velocity $u_{f}$ and (b) frontheight $h_{f}$ at the impact, as a function of the initial height $H_{i}$ of the column for fluidized granular (black circles) and salt water (blue squares) flows, with $\theta=15^{\circ}$. The orange arrows indicate the value of $u_{f}$ and $h_{f}$, with $H_{i} \sim 0.8 \mathrm{~m}$, for a dry granular flow. The solid line, gray area and dotted line are defined in the caption of Figure 3.

Before addressing the wave amplitude as a function of the flowing material, the typical dynamics of dry granular, fluidized granular, and salt water flows is investigated. For the sake of simplicity and only in this section, the origin of the coordinate system $(x, y)$ is shifted at the position of the sluice gate along the inclined plane. In this way, dimen- 
sionless variables can be defined as

$$
\widehat{x}=\frac{x}{x^{I}}, \quad \widehat{h}=\frac{h\left(x, t^{I}\right)}{h\left(0, t^{I}\right)}, \quad \widehat{t}=\frac{t}{t^{I}},
$$

where $x^{I}$ and $t^{I}$ correspond to the position of the shoreline and the time at which the granular flow impacts water, respectively.

Figure 9a shows the normalized front position $\widehat{x}_{f}$ as a function of the normalized time $\widehat{t}$, for dry granular, fluidized granular, and salt water flows. In the latter two cases, the curve corresponds to the average of three experiments with different mass flux per width and volume per width in the range $q_{m}=[26: 116] \mathrm{kg} \cdot \mathrm{m}^{-1} \cdot \mathrm{s}^{-1}$ and $v=[5.2$ : 13.2] $\mathrm{dm}^{2}$, respectively. The temporal evolution of the front position collapses on a single curve, regardless of the flowing material. In each case, the front accelerates before to reach a constant-front velocity $\widehat{x}_{f}=1.15 \widehat{t}$ (solid line), until entering water. Moreover, the trend of the constant flow front-velocity $u_{f}$ with the initial height of the column $H_{i}$ is similar for fluidized granular (black circles) and salt water (blue squares) flows, as shown in the inset of Figure 9a. In the case of dry granular flows, however, $u_{f}$ is much lower compared to fluidized granular and salt water flows, for a given $H_{i}$. More specifically, for a dry granular flow, $u_{f} \sim 2.0 \mathrm{~m} . \mathrm{s}^{-1}$ with $H_{i} \sim 0.8 \mathrm{~m}$ (orange arrow), which is outside the range shown in the inset of Figure 9a.

Figure 9 (b) shows the typical height profile $\widehat{h}$ of fluidized granular, salt water, and dry granular flows at the impact, for the same set of experiments. First, the height profile of dry granular flows is strongly different from that of fluidized granular and salt water flows. Indeed, the height profile of dry granular flows is concave upward with a height that tends rapidly toward zero, while it is more convex upward with a thick front for fluidized granular and salt water flows. In the latter two cases, the height profile matches very well together, which supports similar dynamics of fluidized granular and water flows, as previously observed in the dam-break configuration on a horizontal plane (Roche et al., 2008). Note that the differences on the height profile morphology between dry granular flows and fluidized granular/salt water flows could affect the dynamics at the impact. Additionally, the trend of the front-height $h_{f}$ as a function of the initial height $H_{i}$ of the column is similar for fluidized granular (black circles) and salt water (blue squares) flows, unlike for dry granular flows (orange arrow) (inset in Figure 9b).

\subsection{Predictive models for the wave amplitude}

Now, the role of the flowing material on the amplitude of the leading and largest wave can be addressed. In particular, the wave amplitude is regarded as a function of dimensionless parameters, namely the Froude number $F r$, the relative thickness $S$, and the relative mass $M$, according to previous works (Fritz et al., 2004; Zweifel et al., 2006; Heller \& Hager, 2010; Zitti et al., 2016; Bullard, Mulligan, Carreira, \& Take, 2019). In the following, the wave amplitude $A$ corresponds to the mean value measured at $x=$ $2,2.4$, and $2.8 \mathrm{~m}$ from the shoreline, while error bars indicate the variation. Values of the dimensionless parameters and of the wave amplitudes are provided in the supporting information (Table S1).

Figure 10a shows the normalized wave amplitude $A / H_{o}$ as a function of the impulse product parameter $P$, for fluidized granular, dry granular, and salt water flows (see legend in Figure 10c). The dashed-dotted line corresponds to the predictive model $A / H_{o}=$ $4 P^{4 / 5} / 9$, proposed by Heller and Hager (2010). Note that, for dry granular flows, the volume per width $v$ corresponds to the effective volume entering water, as a granular deposit forms on the subaerial ramp with a slope angle $\theta<\alpha_{r}$. Qualitatively, both the experimental data and the predictive model follow a similar trend, with in particular, $A / H_{o}$ increasing for $P$ increasing. Additionally, the scatter of results is included in the inaccuracy range of $\pm 30 \%$, observed by Heller and Hager (2010). Quantitatively, however, the general trend of experimental data is underestimated by the predictive model. 

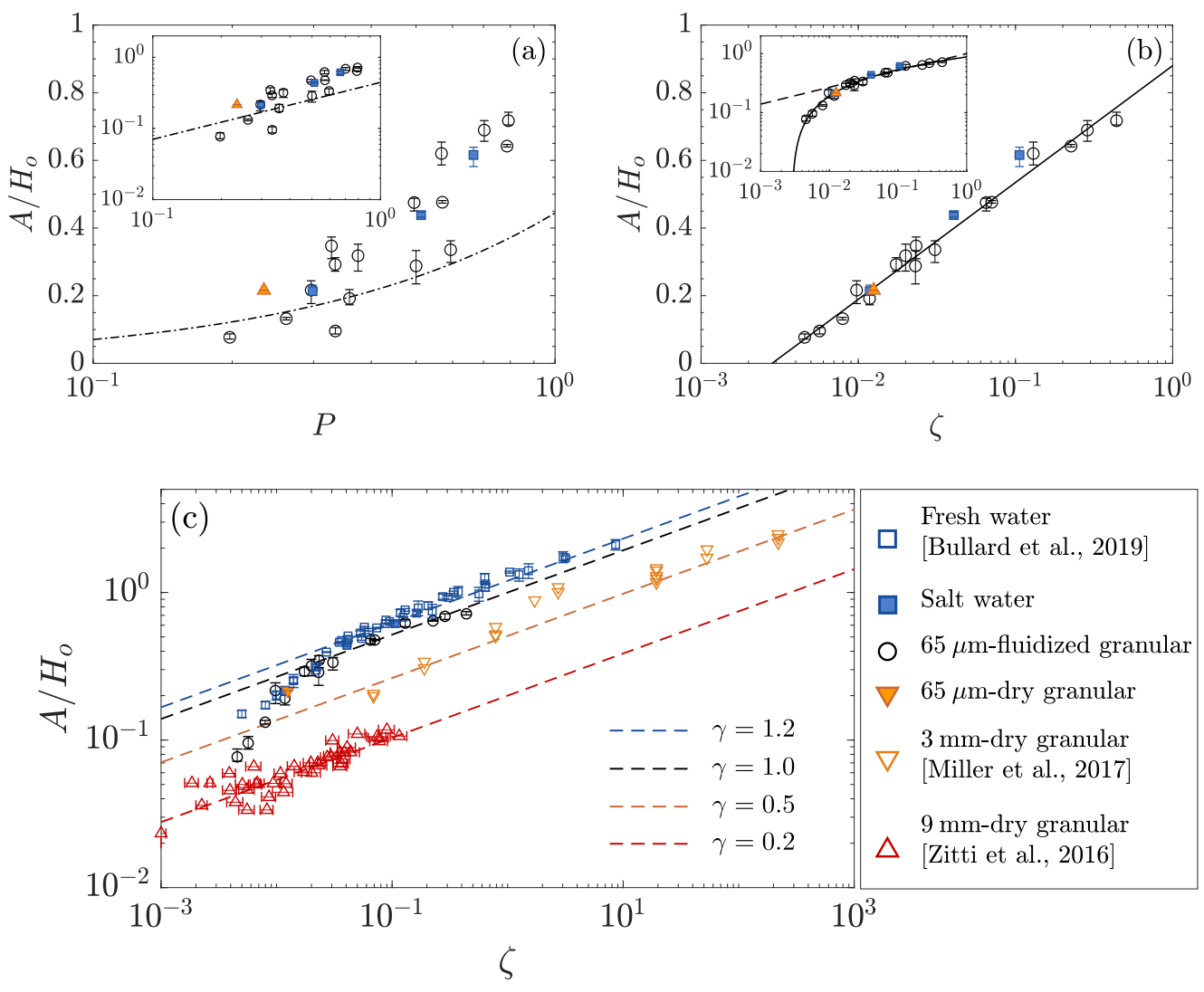

Figure 10. Dimensionless amplitude $A / H_{o}$ as a function of (a) the impulse product parameter $P$ (equation (1)) and (b,c) the parameter $\zeta$ (equation (4)) for different flowing materials (insets: $\log -\log$ representation). In (a), (- - - - ) $A / H_{o}=4 P^{4 / 5} / 9$ (Heller \& Hager, 2010). In (b), (-) $A / H_{o}=0.15 \ln \zeta+0.88$. In (b) and (c), (- -) $A / H_{o}=\gamma \zeta^{2 / 7}$.

Moreover, the dimensionless parameter $P$ leads to a significant inaccuracy on the estimate of the wave amplitude.

To improve the predictive model here, the exponents of equation (1) are set to obtain the best fit with our experimental results, in the case of fluidized granular flows. A better agreement is also obtained considering the vertical component of the flow velocity $u_{f} \sin \theta$, which differs from previous studies that considered the horizontal component (Zweifel et al., 2006; Heller \& Hager, 2010; Mulligan \& Take, 2017). This may be discussed considering end-member configurations: A flow at slope angle of $\theta=0^{\circ}$ would travel at the water surface without significant basal shear, whereas a flow impacting the water surface at $\theta=90^{\circ}$ would cause displacement of the fluid enhancing the wave generation. Thus, we redefine the dimensionless number such as

$$
\zeta=\left(\frac{u_{f}}{\sqrt{g H_{o}}}\right)\left(\frac{h_{f}}{H_{o}}\right)\left(\frac{\rho}{\rho_{f}} \frac{v}{H_{o}^{2}}\right) \sin \theta=F r S M \sin \theta .
$$

With this redefined parameter, the effect of the mass flux per width $q_{m}=\rho u_{f} h_{f}$ and of the volume per width $v$ of similar magnitude on the wave amplitude $A$ is recovered, that is, $\zeta \propto q_{m} v$.

Figure 10b shows the normalized amplitude $A / H_{o}$ as a function of the dimensionless parameter $\zeta$, for fluidized granular, dry granular, and salt water flows. First, the pa- 
rameter $\zeta$ allows to collapse all data for fluidized granular flows on a master curve with a low inaccuracy of $\pm 5 \%$. A gross estimate gives $A / H_{o}=0.15 \ln \zeta+0.88$ (solid line). More precisely, for $\zeta \gtrsim 0.02$, the data of fluidized granular flows collapse on a slope $2 / 7$ (dashed line in inset of Figure 10b), leading to $A / H_{o} \sim \zeta^{2 / 7} \sim 1 / H_{o}$. At large $\zeta$, the $H_{o}$ independency of the leading wave amplitude in the near-field region, as previously mentioned in section 5.3, is therefore recovered. The experimental data deviate from the slope $2 / 7$, at $\zeta \lesssim 0.02$. Secondly, our data for fluidized granular, dry granular and salt water flows collapse on the master curve. In the range of parameters considered here, our experiments provide the unexpected result that the nature of the flowing material can be disregarded to predict the wave amplitude, and only the flow conditions (e.g., bulk density, volume, and velocity) have to be considered. The phenomenon of wave generation is therefore partly controlled by the flow kinematics, which depends on source conditions and material properties. Our results suggest also that ash-rich pyroclastic flows can be considered as single-phase media in the context of experimental and numerical modeling. However, some caution is required as only the wave amplitude has been considered here.

A further step is to confront our results with data available in the literature, under different flow conditions. Zitti et al. (2016), Miller et al. (2017), and Bullard, Mulligan, Carreira, and Take (2019) investigated the wave generation by $9 \mathrm{~mm}$-positively buoyant granular, $3 \mathrm{~mm}$-negatively buoyant granular, and fresh water flows, respectively. Note that Miller et al. (2017) and Bullard, Mulligan, Carreira, and Take (2019)'s data can be compared directly together, as the experiments were performed in the same conditions (experimental setup, measurement method). In the case of fresh water flows, the data match fairly well with that of our experiments that involved salt water, $65 \mu \mathrm{m}$-fluidized granular and $65 \mu \mathrm{m}$-dry granular flows. In particular, the case of fresh and salt water flows collapse very well together, while the method to estimate the thickness and the velocity of the flow, in both studies, is slightly different. Overall, at large $\zeta$, it is obtained $A / H_{o}=\gamma \zeta^{2 / 7}$, with $\gamma=1.0$ for the present study, and $\gamma=1.2$ for that of Bullard, Mulligan, Carreira, and Take (2019). In contrast, the leading and largest waves generated by coarse granular flows are significantly smaller, with $\gamma=0.5$ and $\gamma=0.2$ for 3 mm-dry granular (Miller et al., 2017) and 9 mm-dry granular (Zitti et al., 2016) flows, respectively (notice that the data correspond to the maximum values of $A / H_{o}$ ). The influence of the grain size on the wave amplitude may be attributed to the porosity of the flowing material, and more particularly, the ability of water to penetrate it. At sufficiently low grain size, the granular flow is equivalent to a nonporous flowing material, leading to a water-like behavior with an efficient energy transfer between the flow and the water body. In contrast, at larger grain size, the energy of the flow transferred to the leading wave is reduced by water penetrating into the granular medium. In this context, it is important to point out that the ability of a liquid (if it is not water) to penetrate a granular material depends on both grain and liquid properties (e.g., viscosity, size and density of grains, and surface tension).

\section{Conclusion}

Novel laboratory experiments on the entrance of fluidized granular flows into water have been carried out, for the purpose of better understanding tsunamis generated by pyroclastic flows. The fluidization process aimed at generating high interstitial gas pore pressure, which is thought to be one of the main cause of the high mobility of pyroclastic flows, was considered to ensure a suitable modeling. In the present study, the mass flux per width $q_{m}$ and the volume per width $v$ of the granular flow, the maximum water depth $H_{o}$ and the slope angle $\theta$ of the inclined plane were varied.

Preliminary observations first showed that the impact of a fluidized granular flow into water led to (i) an initial single vertical granular jet over water, (ii) a leading wave, corresponding to the largest one, which may be followed by low-amplitude waves, and 
(iii) a turbulent mixing zone forming a turbidity current. This study focused on the description of the leading and largest wave features and disregarded the flow dynamics of the turbidity current. It was shown that the wave features were mainly controlled by $q_{m}$ and $v$ with the same order of magnitude. More specifically, at low $q_{m}$ and $v$, a smooth, slightly nonlinear, moderate-amplitude leading wave followed by low-amplitude waves was obtained while, at large $q_{m}$ and $v$, only a single steep, strongly nonlinear, large-amplitude wave was observed. Overall, the wave types obtained were Stokes to cnoidal in the intermediate water depth conditions, in the range of parameters considered. Additionally, it was shown that the maximum water depth $H_{o}$ did not affect the wave features in the near-field region. In particular, the wave velocity was independent on $H_{o}$, at least up to a distance of $x / l_{1} \sim 2$ from the shoreline. Finally, the amplitude of the leading wave generated by fluidized granular, dry granular (nonfluidized) and water flows was compared. To this end, a dimensionless parameter was defined as $\zeta=F r S M \sin \theta$, depending on the Froude number $F r$, the relative flow thickness $S$, the relative mass $M$, and the slope angle $\theta$. With this parameter, the data for fluidized granular flows collapsed on a master curve with a low inaccuracy of $\pm 5 \%$. For $\zeta \gtrsim 0.02$, the dimensionless amplitude $A / H_{o}$ scaled as $1 / H_{o}$, hence supporting the $H_{o}$-independency in the near-field region. Moreover, this scaling law was used to compare the waves generated by dry granular, fluidized granular, or water flows entering water. It was first shown that the flow dynamics of fine-grained fluidized granular and water flows were strictly equivalent at the impact, differing clearly from dry granular flows. Secondly, fine-grained fluidized, finegrained dry and water flows generated similar leading wave amplitudes. In contrast, coarse granular flows generate lower wave amplitudes, which was attributed to the ability of water to penetrate the flowing material, depending on both the grain and liquid (if it is not water) properties.

In the geophysical context, the present study showed that the wave features may be mainly controlled by both the flow dynamics and the volume of gravity-driven flows that enter water. It is therefore expected that rapid flows, like pyroclastic density currents and debris flows, generate larger waves than other natural flows, for a similar volume. Moreover, the ability of water to penetrate such flows could affect the wave amplitude. For the purpose of volcanic tsunamis, pyroclastic flows are usually composed of a large amount of fine ash and may have high gas pore pressure, two factors likely to prevent the penetration of water into the flow. Such flows are therefore expected to promote the generation of large tsunamis. Finally, this study provided the unexpected result that ash-rich pyroclastic flows can be considered as single-phase media in the context of experimental and numerical studies.

\section{Acknowledgments}

This work was funded by the ANR RAVEX (ANR-16-CE03-0002) project. This is ClerVolc contribution no. 405. The authors acknowledge the support of the technical staff of the Laboratoire Magmas et Volcans (M. Nivoix, E. Brut, J.-L. Fruquière, C. Guillot) for their contribution in designing and constructing the experimental setup. A. Bougouin is grateful to S. Abadie, M. Cabrera, H. E. Huppert, L. Lacaze, Y. Le Guer, and S. Viroulet for fruitful discussions. We thank R. P. Mulligan and F. Løvholt for the constructive comments that helped to greatly improve the initial manuscript. Data presented in this paper are in open access at https://doi.org/10.6084/m9.figshare.10070183.v1.

\section{References}

Allen, S. R., Freundt, A., \& Kurokawa, K. (2012). Characteristics of submarine pumice-rich density current deposits sourced from turbulent mixing of subaerial pyroclastic flows at the shoreline: field and experimental assessment. Bull. Volcanol., 74, 657-675. 
Ancey, C., Iverson, R. M., Rentschler, M., \& Denlinger, R. P. (2008). An exact solution for ideal dam-break floods on steep slopes. Water Resour. Res., 44 , W01430.

Ataie-Ashtiani, B., \& Nik-Khah, A. (2008). Impulsive waves caused by subaerial landslides. Env. Fluid Mech., 8, 263-280.

Bonometti, T., Balachandar, S., \& Magnaudet, J. (2008). Wall effects in nonBoussinesq density currents. J. Fluid Mech., 616, 445-475.

Bougouin, A., Lacaze, L., \& Bonometti, T. (2017). Collapse of a neutrally buoyant suspension column: from Newtonian to apparent non-Newtonian flow regimes. J. Fluid Mech., 826, 918-941.

Bougouin, A., Paris, R., \& Roche, O. (2019). Ecoulement granulaire fluidisé impactant l'eau: Application aux tsunamis volcaniques. In 24ème congrès français de mécanique.

Breard, E. C. P., Dufek, J., \& Lube, G. (2018). Enhanced mobility in concentrated pyroclastic density currents: An examination of a self-fluidization mechanism. Geophys. Res. Lett., 45, 654-664.

Bullard, G. K., Mulligan, R. P., Carreira, A., \& Take, W. A. (2019). Experimental analysis of tsunamis generated by the impact of landslides with high mobility. Coast. Eng., 152, 103538.

Bullard, G. K., Mulligan, R. P., \& Take, W. A. (2019). An enhanced framework to quantify the shape of impulse waves using asymmetry. J. Geophys. Res., 124, 652-666.

Carey, S., Morelli, D., Sigurdsson, H., \& Bronto, S. (2001). Tsunami deposits from major explosive eruptions: An example from the 1883 eruption of Krakatau. Geology, 29, 347-350.

Chédeville, C., \& Roche, O. (2014). Autofluidization of pyroclastic flows propagating on rough substrates as shown by laboratory experiments. J. Geophys. Res., 119, 1764-1776.

Chédeville, C., \& Roche, O. (2018). Autofluidization of collapsing bed of fine particles: Implications for the emplacement of pyroclastic flows. J. Volcanol. Geotherm. Res., 368, 91-99.

Clous, L., \& Abadie, S. (2019). Simulation of energy transfers in waves generated by granular slides. Landslides, 16, 1663-1679.

De Lange, W. P., Prasetya, G. S., \& Healy, T. R. (2001). Modelling of tsunamis generated by pyroclastic flows (ignimbrites). Nat. Hazards, 24, 251-266.

Delannay, R., Valance, A., Mangeney, A., Roche, O., \& Richard, P. (2017). Granular and particle-laden flows: from laboratory experiments to field observations. $J$. Phys. D, 50, 053001.

Dressler, R. F. (1952). Hydraulic resistance effect upon the dam-break functions. J. Res. Natl. Bur. Stand., 49, 217-225.

Dressler, R. F. (1954). Comparison of theories and experiments for the hydraulic dam-break wave. Int. Assoc. Sci. Hydrology, 3, 319-328.

Dufek, J. (2016). The fluid mechanics of pyroclastic density currents. Ann. Rev. Fluid Mech., 48, 459-485.

Dufek, J., \& Manga, M. (2008). In situ production of ash in pyroclastic flows. J. Geophys. Res., 113, B09207.

Farin, M., Mangeney, A., \& Roche, O. (2014). Fundamental changes of granular flow dynamics, deposition, and erosion processes at high slope angles: Insights from laboratory. J. Geophys. Res., 119, 504-532.

Freundt, A. (2003). Entrance of hot pyroclastic flows into the sea: Experimental observations. Bull. Volcanol., 65, 144-164.

Fritz, H. M., Hager, W. H., \& Minor, H.-E. (2003a). Landslide generated impulse waves. 1. Instantaneous flow fields. Exp. Fluids, 35, 505-519.

Fritz, H. M., Hager, W. H., \& Minor, H.-E. (2003b). Landslide generated impulse waves. 2. Hydrodynamic impact craters. Exp. Fluids, 35, 520-532. 
Fritz, H. M., Hager, W. H., \& Minor, H.-E. $\quad$ (2004). Near field characteristics of landslide generated impulse waves. J. Waterway, Port, Coast. Ocean Eng., 130, 287-302.

Girolami, L., Druitt, T. H., Roche, O., \& Khrabrykh, Z. (2008). Propagation and hindered settling of laboratory ash flows. J. Geophys. Res., 113, B02202.

Gouhier, M., \& Paris, R. (2019). SO2 and tephra emissions during the December 22, 2018 Anak Krakatau flank-collapse eruption. Volcanica, 2, 91-103.

Gravish, N., \& Goldman, D. I. (2014). Effect of volume fraction on granular avalanche dynamics. Phys. Rev. E, 90, 032202.

Grezio, A., Babeyko, A., Baptista, M. A., Behrens, J., Costa, A., Davies, G., ... Kie Thio, H. (2017). Probabilistic tsunami hazard analysis: Multiple sources and global applications. Rev. Geophys., 55, 1158-1198.

Grilli, S. T., Tappin, D. R., Carey, S., Watt, S. F. L., Ward, S. N., Grilli, A. R., ... Muin, M. (2019). Modelling of the tsunami from the December 22, 2018 lateral collapse of Anak Krakatau volcano in the Sunda Straits, Indonesia. Sci. Reports, 9, 11946.

Harbitz, C. B., Løvholt, F., Pedersen, G., \& Masson, D. G. (2006). Mechanisms of tsunami generation by submarine landslides: a short review. Nor. J. Geol., $86(3)$.

Heinrich, P. (1992). Nonlinear water waves generated by submarine and aerial landslides. J. Waterway, Port, Coast. Ocean Eng., 118, 249-266.

Heller, V., Bruggemann, M., Spinneken, J., \& Rogers, B. D. (2016). Composite modelling of subaerial landslide-tsunamis in different water body geometries and novel insight into slide and wave kinematics. Coast. Eng., 109, 20-41.

Heller, V., Chen, F., Brühl, M., Gabl, R., Chen, X., Wolters, G., \& Fuchs, H. (2019). Large-scale experiments into the tsunamigenic potential of different iceberg calving mechanisms. Sci. Rep., 9.

Heller, V., \& Hager, W. H. (2010). Impulse product parameter in landslide generated impulse waves. J. Waterway, Port, Coast. Ocean Eng., 136, 145-155.

Heller, V., \& Hager, W. H. (2011). Wave types of landslide generated impulse waves. Ocean Eng., 38, 630-640.

Heller, V., \& Kinnear, R. D. (2010). Discussion of Experimental investigation of impact generated tsunami; related to a potential rock slide, Western Norway by G. Sælevik, A. Jensen, G. Pedersen [Coastal Eng. 56 (2009) 897-906]. Coast. Eng., 57, 773-777.

Heller, V., \& Spinneken, J. (2015). On the effect of the water body geometry on landslide-tsunamis: Physical insight from laboratory tests and 2D to 3D wave parameter transformation. Coast. Eng. J., 104, 113-134.

Hogg, A. J., \& Pritchard, D. (2004). The effects of hydraulic resistance on dambreak and other shallow inertial flows. J. Fluid Mech., 501, 179-212.

Hogg, A. J., \& Woods, A. W. (2001). The transition from inertia- to bottomdrag-dominated motion of turbulent gravity currents. J. Fluid Mech., 449, 201-224.

Jánosi, I. M., Jan, D., Szabó, K. G., \& Tél, T. (2004). Turbulent drag reduction in dam-break flows. Exp. Fluids, 37, 219-229.

Kamphuis, J. W., \& Bowering, R. J. (1970). Impulse waves generated by landslides. In Proc. of 12th Coastal Engineering Conference, New York, United States.

Kneller, B., \& Buckee, C. (2000). The structure and fluid mechanics of turbidity currents: a review of some recent studies and their geological implications. Sedimentology, 47, 62-94.

Latter, J. H. (1981). Tsunamis of volcanic origin: Summary of causes, with particular reference to Krakatoa, 1883. Bull. Volcanol., 44, 467-490.

Law, L., \& Brebner, A. (1968). On water waves generated by landslides. In Proc. of the Third Australasian Conference on Hydraulics and Fluid Mechanics, Sydney, Australia. 
Lay, T., Kanamori, H., Ammon, J., Nettles, M., Ward, S. N., Aster, R. C., ... Sipkin, S. (2005). The great Sumatra-Andaman earthquake of 26 december 2004. Science, 308, 1127-1133.

Leal, J. G., Ferreira, R. M., \& Cardoso, A. H. (2006). Dam-break wave-front velocity. J. Hydraul. Res., 132, 69-76.

Le Méhauté, B. (1976). An introduction to hydrodynamics and water waves. Springer, New York.

Lindstrøm, E. K. (2016). Waves generated by subaerial slides with various porosities. Coast. Eng. J., 116, 170-179.

Løvholt, F., Pedersen, G., Harbitz, C. B., Glimsdal, S., \& Kim, J. (2015). On the characteristics of landslide tsunamis. Phil. Trans. R. Soc. A, 373, 20140376.

Lube, G., Breard, E. C. P., Jones, J., Fullard, L., Dufek, J., Cronin, S. J., \& Wang, T. (2019). Generation of air lubrication within pyroclastic density currents. Nat. Geosci., 12, 381-386.

Maeno, F., \& Imanura, F. (2011). Tsunami generation by a rapid entrance of pyroclastic flow into the sea during the 1883 krakatau eruption, indonesia. J. Geophys. Res., 116, B09205.

Mangeney, A., Roche, O., Hungr, O., Mangold, N., Faccanoni, G., \& Lucas, A. (2010). Erosion and mobility in granular collapse over sloping beds. J. Geophys. Res., 115, F03040.

Mattioli, G. S., Voight, B., Linde, A. T., Sacks, I. S., Watts, P., Widiwijayanti, C., ... Williams, D. (2007). Unique and remarkable dilatometer measurements of pyroclastic flow-generated tsunamis. Geology, 35, 25-28.

McCowan, J. (1894). On the highest wave of permanent type. Philos. Mag. Series 5 , $38,351-358$.

Michell, J. H. (1893). The highest waves in water. Philos. Mag. Series 5, 36, 430437.

Miller, G. S., Andy T., W., Mulligan, R. P., \& McDougall, S. (2017). Tsunamis generated by long and thin granular landslides in a large flume. J. Geophys. Res., 122, 653-668.

Mohammed, F., \& Fritz, H. M. (2012). Physical modeling of tsunamis generated by three-dimensional deformable granular landslides. J. Geophys. Res., 117, C11015

Monaghan, J. J., Kos, A., \& Issa, N. (2003). Fluid motion generated by impact. J. Waterway, Port, Coast. Ocean Eng., 129.

Montserrat, S., Tamburrino, A., Roche, O., \& Niño, Y. (2012). Pore fluid pressure diffusion in defluidizing granular columns. J. Geophys. Res., 117, F02034.

Mulligan, R. P., \& Take, W. A. (2017). On the transfer of momentum from a granular landslide to a water wave. Coast. Eng., 125, 16-22.

Nishimura, Y., Nakagawa, M., Kuduon, J., \& Wukawa, J. (2005). Timing and scale of tsunamis caused by the 1994 Rabaul eruption, East New Britain, Papua New Guinea. In Tsunamis (pp. 43-56). Springer.

Nomanbhoy, N., \& Satake, K. (1995). Generation mechanism of tsunamis from the 1883 Krakatau eruption. Geophys. Res. Lett., 22, 509-512.

Nomikou, P., Druitt, T. H., Hübscher, C., Mather, T. A., Paulatto, M., Kalnins, L. M., ... Parks, M. M. (2016). Post-eruptive flooding of Santorini caldera and implications for tsunami generation. Nat. Commun., 7, 13332.

Paris, R. (2015). Source mechanisms of volcanic tsunamis. Phil. Trans. R. Soc. A, 373, 20140380.

Paris, R., Switzer, A. D., Belousova, M., Belousov, A., Ontowirjo, B., Whelley, P. L., \& Ulvrova, M. (2014). Volcanic tsunami: a review of source mechanisms, past events and hazards in Southeast Asia (Indonesia, Philippines, Papua New Guinea). Nat. Hazards, 70, 447-470.

Paris, R., Wassmer, P., Lavigne, F., Belousov, A., Belousova, M., Iskandarsyah, Y., ... Mazzoni, N. (2014). Coupling eruption and tsunami records: the Krakatau 
1883 case study, Indonesia. Bull. Volcanol., $76,814$.

Pelinovsky, E., Zahibo, N., Dunkley, P., Edmonds, M., Herd, R., Talipova, T., ... Nikolkina, I. (2004). Tsunami generated by the volcano eruption on July 12-13, 2003 at Montserrat, Lesser Antilles. Sci. Tsunami Hazards, 22, 44-57.

Pouliquen, O. (1999). Scaling laws in granular flows down rough inclined planes. Phys. Fluids, 11, 542-548.

Ritter, A. (1892). Die fortpflanzung der wasserwellen. Z. Verein Deutch. Ing., 36, 947-954.

Roche, O. (2012). Depositional processes and gas pore pressure in pyroclastic flows: an experimental perspective. Bull. Volcanol., 74, 1807-1820.

Roche, O., Attali, M., Mangeney, A., \& Lucas, A. (2011). On the run-out distance of geophysical gravitational flows: Insight from fluidized granular collapse experiments. Earth Planet. Sci. Lett., 311, 375-385.

Roche, O., Gilbertson, M., Phillips, J. C., \& Sparks, R. S. J. (2002). Experiments on deaerating granular flows and implications for pyroclastic flow mobility. Geophys. Res. Lett., 29, 1792.

Roche, O., Montserrat, S., Niño, Y., \& Tamburrino, A. (2008). Experimental observations of water-like behavior of initially fluidized, dam break granular flows and their relevance for the propagation of ash-rich pyroclastic flows. $J$ Geophys. Res., 113, B12203.

Rowley, P. J., Roche, O., Druitt, T. H., \& Cas, R. A. F. (2014). Experimental study of dense pyroclastic density currents using sustained, gas-fluidized granular flows. Bull. Volcanol., 76, 855.

Smith, G. M., Williams, R., Rowley, P. J., \& Parsons, D. R. (2018). Investigation of variable aeration of monodisperse mixtures: Implications for pyroclastic density currents. Bull. Volcanol., 80, 67.

Soria-Hoyo, C., Valverde, J. M., \& Roche, O. (2019). A laboratory-scale study on the role of mechanical vibrations in pore pressure generation in pyroclastic materials: Implications for pyroclastic flows. Bull. Volcanol., 81, 12.

Sparks, R. S. J. (1976). Grain size variations in ignimbrites and implications for the transport of pyroclastic flows. Sedimentology, 23, 147-188.

Tanguy, J.-C., Ribière, C., Scarth, A., \& Tjetjep, W. S. (1998). Victims from volcanic eruptions: a revised database. Bull. Volcanol., 60, 137-144.

Valverde, J. M., \& Soria-Hoyo, C. (2015). Vibration-induced dynamical weakening of pyroclastic flows: Insights from rotating drum experiments. J. Geophys. Res., 120, 6182-6190.

Verbeek, R. D. M. (1886). Krakatau. Imprimerie de l'Etat, Batavia (Indonesia).

Viroulet, S., Cébron, D., Kimmoun, O., \& Kharif, C. (2013). Shallow water waves generated by subaerial solid landslides. Geophys. J. Int., 193, 747-762.

Viroulet, S., Sauret, A., \& Kimmoun, O. (2014). Tsunami generated by a granular collapse down a rough inclined plane. EPL, 105, 34004.

Walder, J. S., Watts, P., Sorensen, O. E., \& Janssen, K. (2003). Tsunamis generated by subaerial mass flows. J. Geophys. Res., 108.

Watts, P., \& Waythomas, C. F. (2003). Theoretical analysis of tsunami generation by pyroclastic flows. J. Geophys. Res., 108, B12, 2563.

Wilson, C. J. N. (1980). The role of fluidization in the emplacement of pyroclastic claws: An experimental approach. J. Volcanol. Geotherm. Res., 8, 231-249.

Wünnemann, K., \& Weiss, R. (2015). The meteorite impact-induced tsunami hazard. Phil. Trans. R. Soc. A, 373, 20140381.

Yavari-Ramshe, S., \& Ataie-Ashtiani, B. (2016). Numerical modeling of subaerial and submarine landslide-generated tsunami waves-recent advances and future challenges. Landslides, 13, 1325-1368.

Yokoyama, I. (1987). A scenario of the 1883 krakatau tsunami. J. Volcanol. Geotherm. Res., 34, 123-132. 
Zitti, G., Ancey, C., Postacchini, M., \& Brocchini, M. (2016). Impulse waves generated by snow avalanches: Momentum and energy transfer to a water body. $J$. Geophys. Res., 121, 2399-2423.

Zweifel, A., Hager, H., \& Minor, H.-E. (2006). Plane impulse waves in reservoirs. J. Waterway, Port, Coast. Ocean Eng., 132, 356-368. 